\title{
The Cost of Transmission for Wind Energy: A Review of Transmission Planning Studies
}

Andrew Mills, Ryan Wiser, and Kevin Porter

\section{Environmental Energy Technologies Division}

February 2009

Download from http://eetd.lbl.gov/EA/EMP

The work described in this report was funded by the Office of Energy Efficiency and Renewable Energy (Wind \& Hydropower Technologies Program) and by the Office of Electricity Delivery and Energy Reliability (Permitting, Siting and Analysis Division) of the U.S. Department of Energy under Contract No. DE-AC02-05CH11231. 


\section{Disclaimer}

This document was prepared as an account of work sponsored by the United States Government. While this document is believed to contain correct information, neither the United States Government nor any agency thereof, nor The Regents of the University of California, nor any of their employees, makes any warranty, express or implied, or assumes any legal responsibility for the accuracy, completeness, or usefulness of any information, apparatus, product, or process disclosed, or represents that its use would not infringe privately owned rights. Reference herein to any specific commercial product, process, or service by its trade name, trademark, manufacturer, or otherwise, does not necessarily constitute or imply its endorsement, recommendation, or favoring by the United States Government or any agency thereof, or The Regents of the University of California. The views and opinions of authors expressed herein do not necessarily state or reflect those of the United States Government or any agency thereof, or The Regents of the University of California.

Ernest Orlando Lawrence Berkeley National Laboratory is an equal opportunity employer. 


\title{
The Cost of Transmission for Wind Energy: A Review of Transmission Planning Studies
}

\author{
Prepared for the \\ Office of Energy Efficiency and Renewable Energy \\ Wind \& Hydropower Technologies Program \\ U.S. Department of Energy \\ Washington, D.C. \\ and the \\ Office of Electricity Delivery and Energy Reliability \\ Permitting, Siting and Analysis Division \\ U.S. Department of Energy \\ Washington, D.C. \\ Principal Authors: \\ Andrew Mills and Ryan Wiser \\ Ernest Orlando Lawrence Berkeley National Laboratory \\ Kevin Porter \\ Exeter Associates \\ 1 Cyclotron Road, MS 90R4000 \\ Berkeley CA 94720-8136
}

February 2009

The work described in this report was funded by the Office of Energy Efficiency and Renewable Energy (Wind \& Hydropower Technologies Program) and by the Office of Electricity Delivery and Energy Reliability (Permitting, Siting and Analysis Division) of the U.S. Department of Energy under Contract No. DE-AC02-05CH11231. 


\section{Acknowledgements}

The work described in this report was funded by the Office of Energy Efficiency and Renewable Energy (Wind \& Hydropower Technologies Program) and by the Office of Electricity Delivery and Energy Reliability (Permitting, Siting and Analysis Division) of the U.S. Department of Energy under Contract No. DE-AC02-05CH11231. We would particularly like to thank Steve Lindenberg, Larry Mansueti, and Patrick Gilman of the U.S. Department of Energy, and Brian Parsons of the National Renewable Energy Laboratory, for their support of this work. For reviewing drafts of this report and/or for providing comments that helped shape our early thinking on this project, we thank Mark Bolinger and Joe Eto (Berkeley Lab), Chris Namovicz (EIA), Jerry Vaninetti (TransElect, LLC), J. Charles Smith (Utility Wind Integration Group), Lynn Coles (NREL), Michael Googin (AWEA), Dale Osborn (MISO), Edgar DeMeo (Renewable Energy Consulting Services, Inc.), Mike Jacobs (UPC Wind Management, LLC), Cliff Chen (Union of Concerned Scientists), and Sara Kamins (California Public Utilities Commission). Of course, any remaining omissions or inaccuracies are our own. 


\section{Table of Contents}

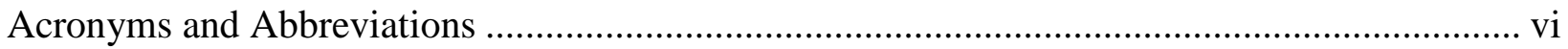

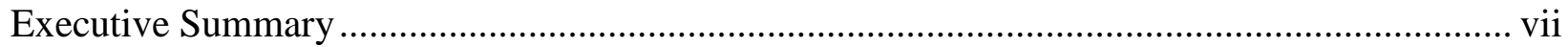

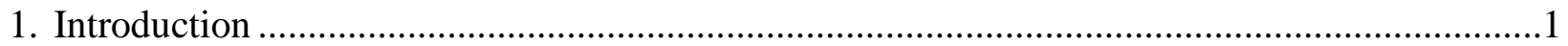

2. Description of Transmission Studies...........................................................................4

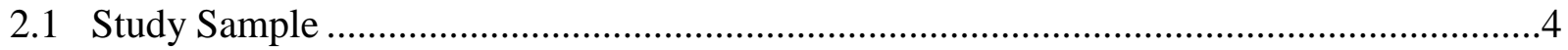

2.2 Degree of Focus on Wind Energy

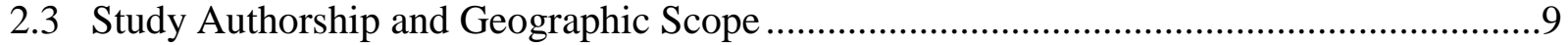

2.4 General Framework: Congestion vs. Deliverability .................................................... 10

2.5 Degree of Transmission Network Interconnectivity .................................................. 13

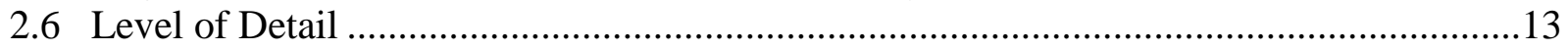

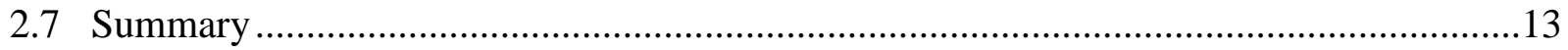

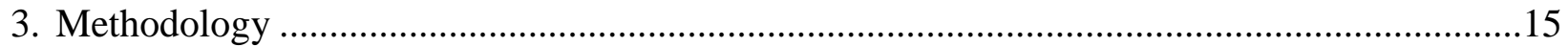

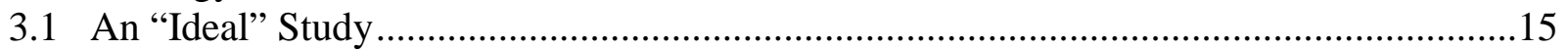

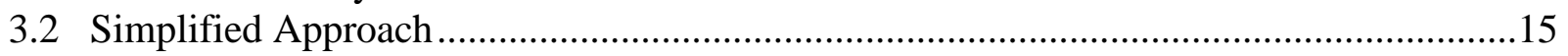

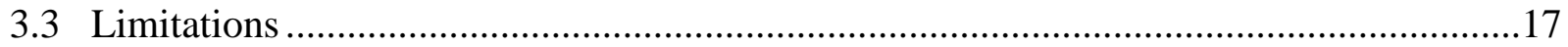

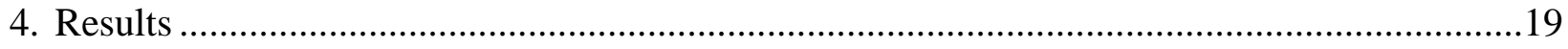

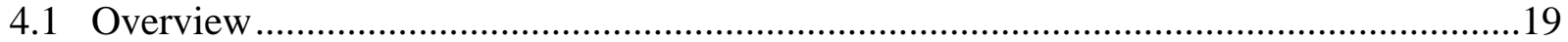

4.2 Implied Unit Cost of Transmission for Wind ...........................................................22

4.3 Effect of Methodological Limitations.........................................................................26

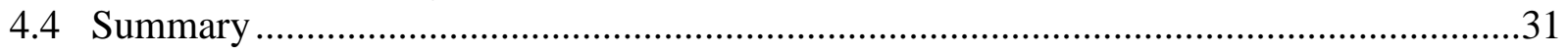

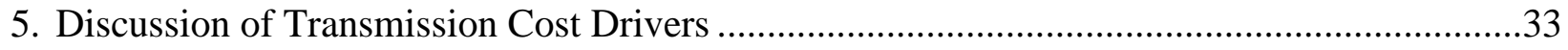

5.1 Amount of Incremental Generation and Voltage of New Transmission .........................33

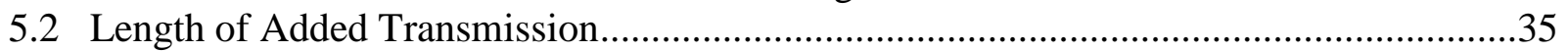

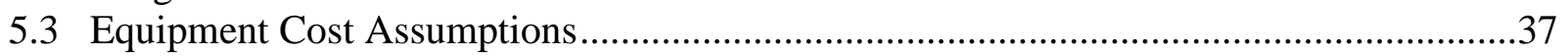

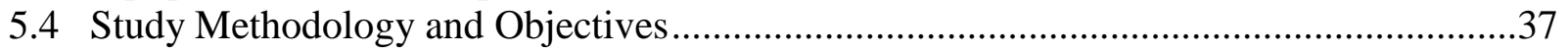

6. Comparison to Top-Down Transmission Cost Estimates ...................................................40

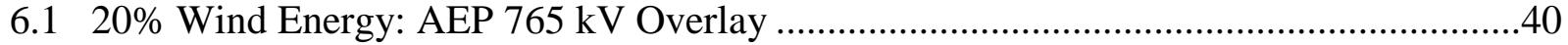

6.2 20\% Wind Energy: Wind Deployment System (WinDS)...........................................41

6.3 NEMS Long-Term (LT) Multipliers.....................................................................42

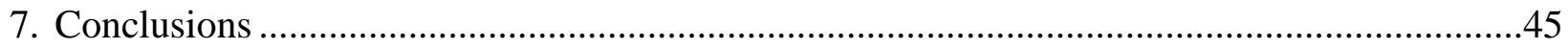

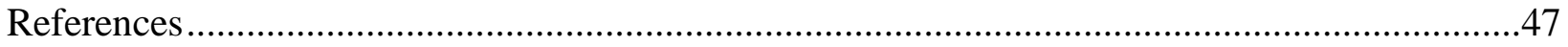

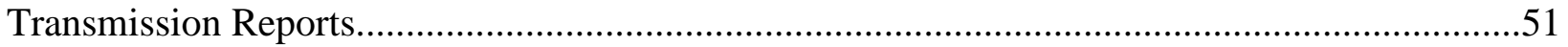




\section{Acronyms and Abbreviations}

$\begin{array}{ll}\text { BRIGO } & \text { Buffalo Ridge Incremental Generation Outlet } \\ \text { CAISO } & \text { California Independent System Operator } \\ \text { CBED } & \text { Community Based Energy Development } \\ \text { CDEAC } & \text { Clean and Diversified Energy Advisory Committee for the WGA } \\ \text { CLRTPG } & \text { Colorado Long-Range Transmission Planning Group } \\ \text { CREZ } & \text { Competitive Renewable Energy Zone } \\ \text { CPUC } & \text { California Public Utilities Commission } \\ \text { EHV } & \text { Extra high voltage } \\ \text { EIA } & \text { Energy Information Administration } \\ \text { EPTP } & \text { Eastern Plains Transmission Project } \\ \text { ERCOT } & \text { Electric Reliability Council of Texas } \\ \text { EWEA } & \text { European Wind Energy Association } \\ \text { FERC } & \text { Federal Energy Regulatory Commission } \\ \text { HPX } & \text { High Plains Express } \\ \text { IAP } & \text { Intermittency Analysis Project } \\ \text { IOU } & \text { Investor owned utility } \\ \text { ISO-NE } & \text { ISO New England } \\ \text { ISO/RTO } & \text { Independent system operator/Regional transmission organization } \\ \text { JCSP } & \text { Joint Coordinated System Plan } \\ \text { MATL } & \text { Montana Alberta Tie Ltd. } \\ \text { MPC } & \text { Maine Power Connection } \\ \text { MISO } & \text { Midwest Independent Transmission System Operator } \\ \text { MSTI } & \text { Mountain States Transmission Intertie } \\ \text { NEMS } & \text { National Energy Modeling System } \\ \text { NERC } & \text { North American Electricity Reliability Corporation } \\ \text { NREL } & \text { National Renewable Energy Laboratory } \\ \text { NTAC } & \text { Northwest Transmission Assessment Committee } \\ \text { NYISO } & \text { New York Independent System Operator } \\ \text { PG\&E } & \text { Pacific Gas \& Electric } \\ \text { PUCT } & \text { Public Utility Commission of Texas } \\ \text { RMATS } & \text { Rocky Mountain Area Transmission Study } \\ \text { SCE } & \text { Southern California Edison } \\ \text { SDG\&E } & \text { San Diego Gas \& Electric } \\ \text { SONGS } & \text { San Onofre Nuclear Generating Station } \\ \text { SPP } & \text { Southwest Power Pool } \\ \text { SSG-WI } & \text { Seams Steering Group of the Western Interconnection } \\ \text { SWAT } & \text { Southwest Area Transmission } \\ \text { TWE\&GS } & \text { TransWest Express and Gateway South } \\ \text { WGA } & \text { Western Governors Association } \\ \text { WinDS } & \text { Wind Deployment System } \\ & \end{array}$




\section{Executive Summary}

\section{Overview}

The rapid development of wind power that the United States has experienced over the last several years has been coupled with a growing concern that wind development will require substantial additions to the nation's transmission infrastructure. Transmission is particularly important for wind power due to the locational dependence of wind resources, the relatively low capacity factor of wind plants, and the mismatch between the short lead time to build a new wind project and the longer lead time often needed to plan, permit, and construct transmission.

It is clear that institutional issues related to transmission planning, siting, and cost allocation will pose major obstacles to accelerated wind power deployment, but also of concern is the potential cost of this infrastructure build out. Simply put, how much extra cost will society bear to deliver wind power to load centers? Without an answer to this question, there can be no consensus on whether or not the cost of developing transmission for wind will be a major barrier to further wind deployment, or whether the institutional barriers to transmission expansion are likely to be of more immediate concern.

\section{Objectives and Methodology}

In this report, we review a sample of 40 detailed transmission studies that have included wind power. These studies cover a broad geographic area, and were completed from 2001-2008. Our primary goal in reviewing these studies is to develop a better understanding of the transmission costs needed to access growing quantities of wind generation. A secondary goal is to gain a better appreciation of the differences in transmission planning approaches in order to identify those methodologies that seem most able to estimate the incremental transmission costs associated with wind development. Finally, we hope that the resulting dataset and discussion might be used to inform the assumptions, methods, and results of higher-level assessment models that are sometimes used to estimate the cost of wind deployment (e.g. NEMS and WinDS).

The authors and general location of the 40 detailed transmission studies included in our review are illustrated in Figure ES-1. As discussed in the body of the report, these studies vary considerably in scope, authorship, objectives, methodology, and tools. Though we recognize this diversity and are cognizant that comparisons among these studies are therefore somewhat inappropriate, we nonetheless emphasize such simple comparisons in this report. We do so in order to improve our understanding of the range of transmission costs needed to access greater quantities of wind, and to highlight some of the drivers of those costs. In so doing, we gloss over many important details and differences among the studies in our sample.

In emphasizing simple comparisons, our analysis focuses primarily on the unit cost of transmission implied by each of the studies. The unit cost of transmission for wind in $\$ / \mathrm{kW}$ terms on a capacity-weighted basis is estimated by simply dividing the total transmission cost in a study by the total amount of incremental generation capacity (wind and non-wind) modeled in that study. In so doing, this metric assumes that within any individual study all incremental 
generation capacity imposes transmission costs in proportion to its nameplate capacity rating. The limitations to this approach are described in some detail in the body of the report.

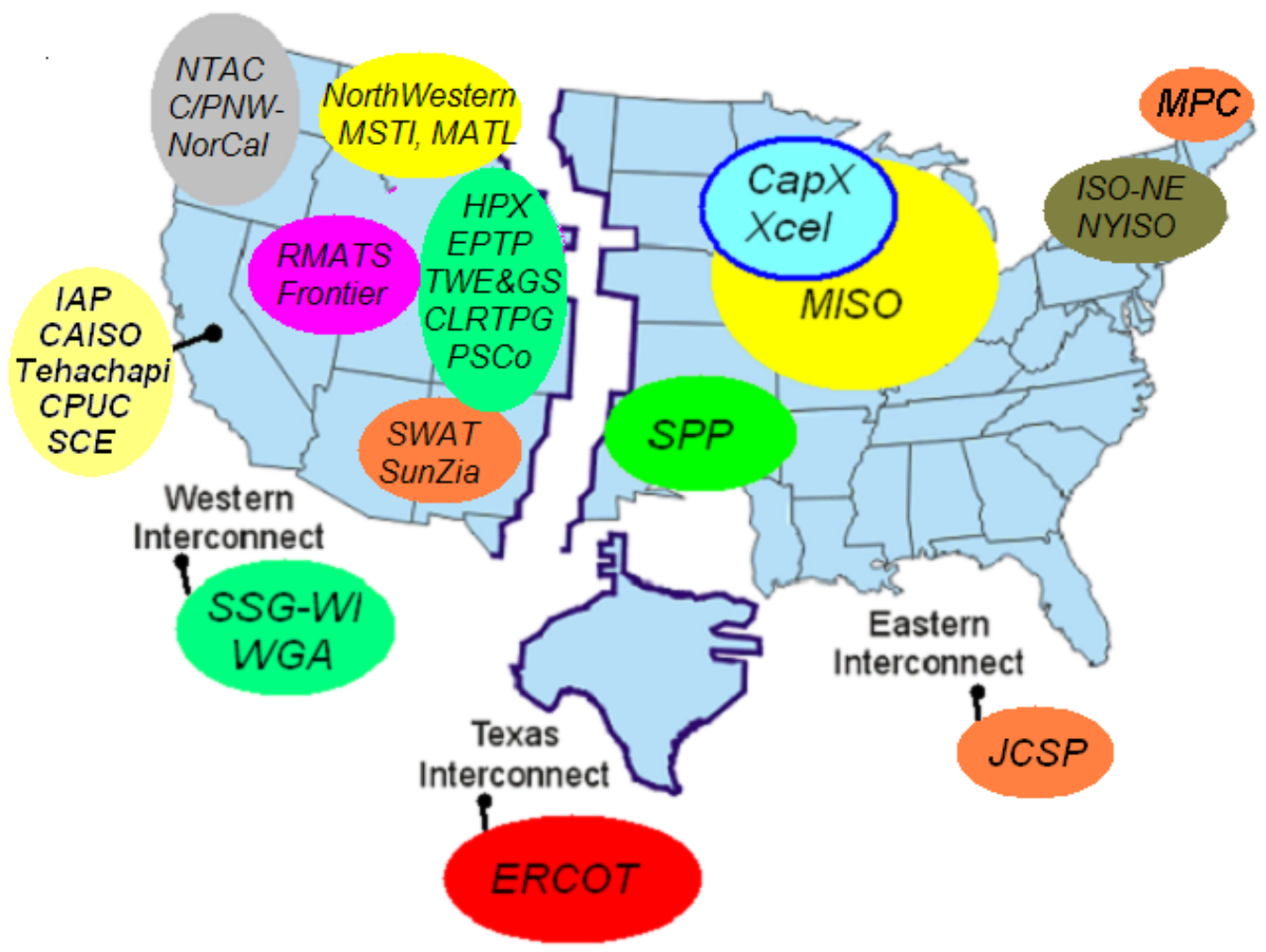

Figure ES- 1. General Geographic Location of Transmission Studies in Sample

\section{Results and Findings}

The resulting unit cost of transmission for wind for our sample of studies is shown in Figure ES2 and 3, in $\$ / \mathrm{kW}$-wind terms and $\$ / \mathrm{MWh}$-wind terms respectively, sorted by increasing unit costs. In cases where a study-scenario involved multiple generation technologies, the total transmission cost of that scenario was allocated to wind on a capacity-weighted basis in both figures. The total amount of incremental wind capacity analyzed by each study scenario ("wind analyzed"), or the total incremental generation capacity in cases when it is not clear what portion of the new capacity is wind ("total analyzed"), is illustrated on the top axis of the figures. As shown, those study-scenarios in our sample that specifically analyze wind power capacity do so with wind additions that range from as little as $63 \mathrm{MW}$ to as much as $236 \mathrm{GW}$. 


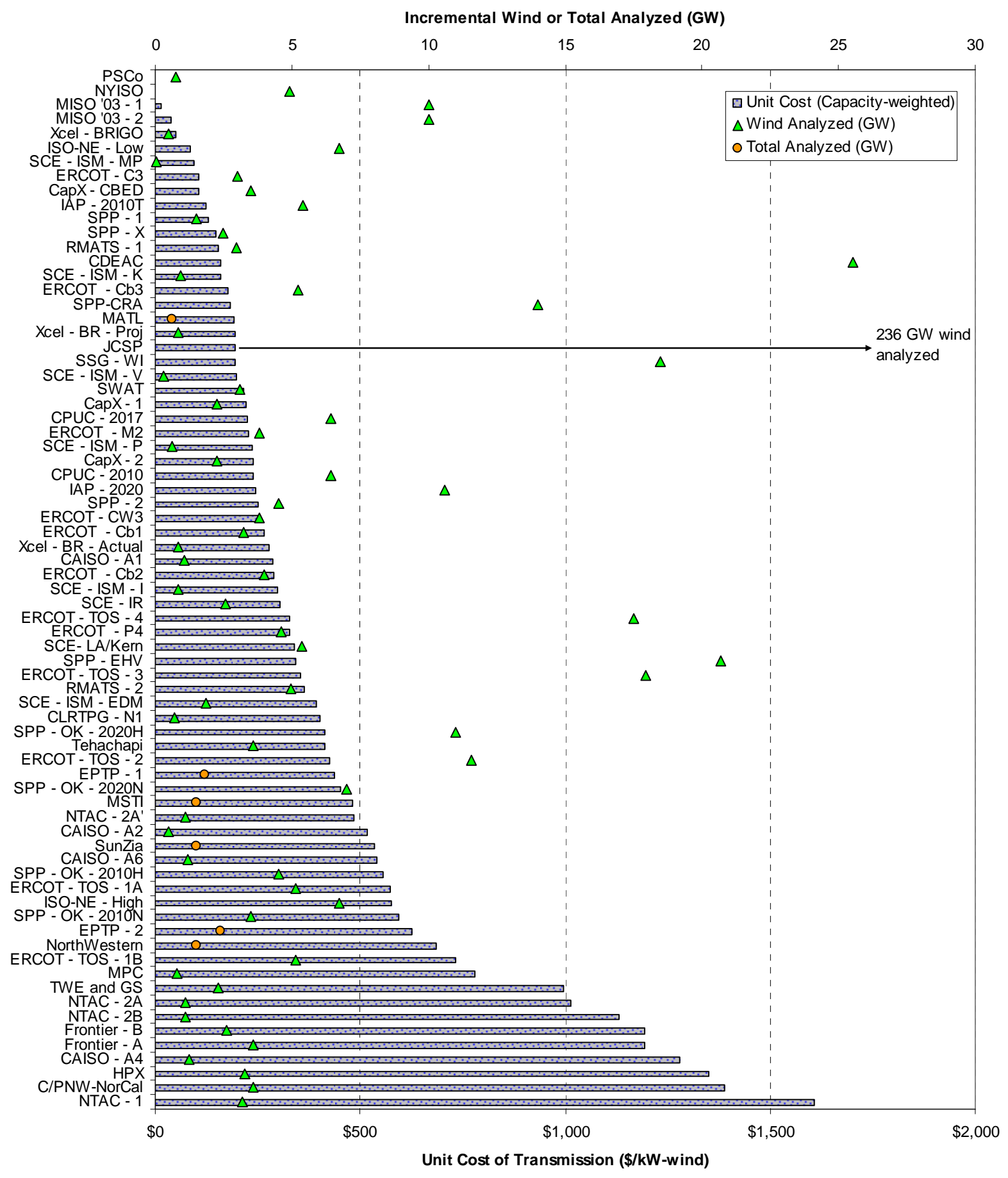

Note: Unit cost of transmission in nominal dollars from various years

\section{Figure ES-2. Unit Cost of Transmission for Wind in $\$ / \mathrm{kW}$-wind Terms}




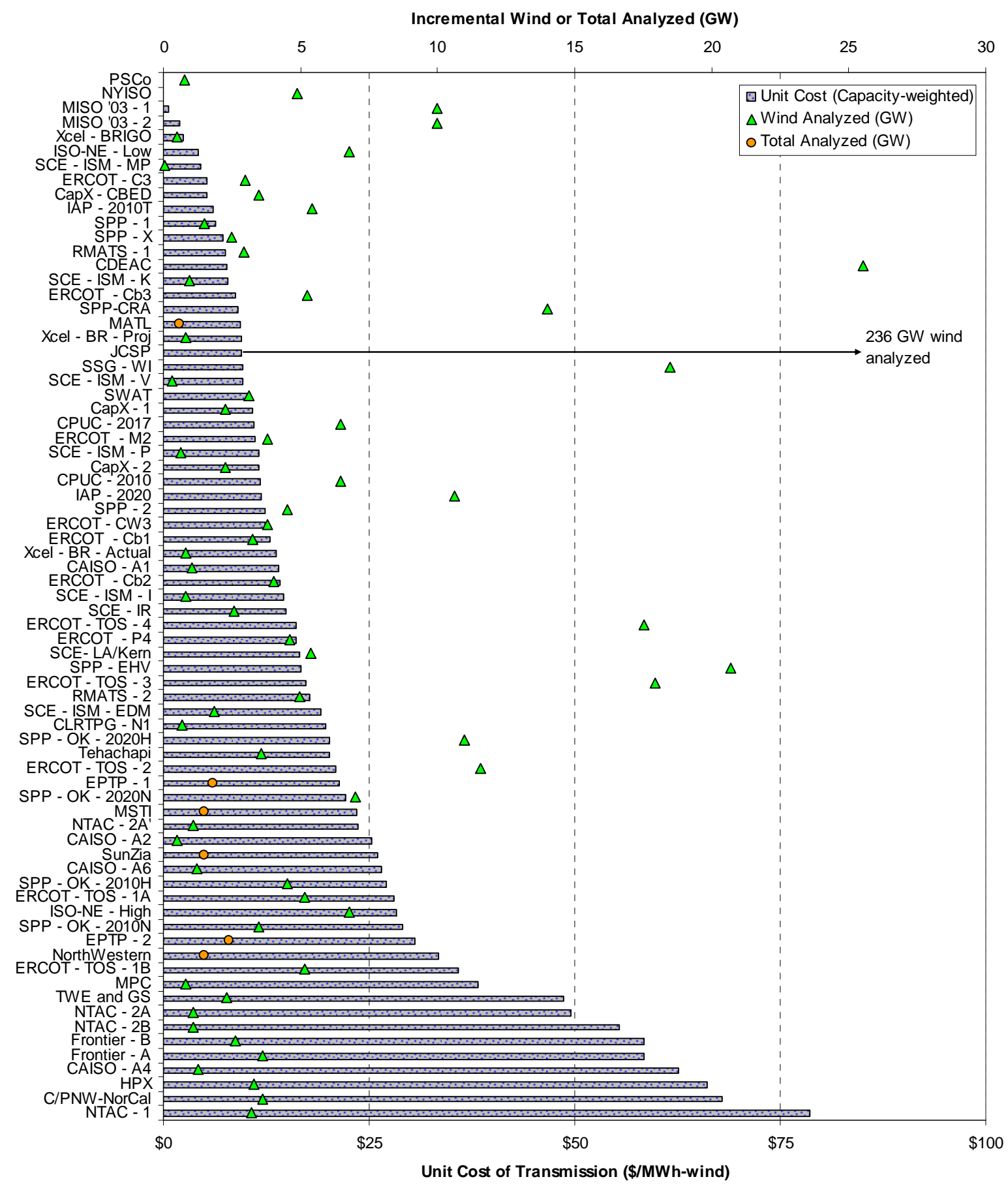

Note: (1) Unit cost of transmission in nominal dollars from various years

(2) Transmission cost levelized using $15 \%$ per year levelizing factor

(3) Energy produced by wind plants calculated assuming 35\% capacity factor for all scenarios

Figure ES-3. Unit Cost of Transmission for Wind in \$/MWh-wind Terms 
The total range in unit transmission costs for wind implicit in these studies is vast - ranging from $\$ 0 / \mathrm{kW}$ to over $\$ 1,500 / \mathrm{kW}$. The majority of studies, however, have a unit cost of transmission that is below $\$ 500 / \mathrm{kW}$, or roughly $25 \%$ of the current $\$ 2,000 / \mathrm{kW}$ cost of building a wind project. The median cost of transmission from all scenarios in our sample is $\$ 300 / \mathrm{kW}$, roughly $15 \%$ of the cost of building a wind project. ${ }^{1}$ In terms of cost per megawatt-hour of wind power generation, the aggregate range of transmission costs is from $\$ 0 / \mathrm{MWh}$ to $\$ 79 / \mathrm{MWh}$, with a median of $\$ 15 / \mathrm{MWh}$ and most studies falling below $\$ 25 / \mathrm{MWh}$.

Though the limitations of our methodology caution against over-interpretation of the results presented here, it is clear that the transmission costs associated with increased wind development are not insignificant. That said, with the exception of a number of high-cost study scenarios, these estimated costs generally add less than $33 \%$ to recent busbar prices of wind-generated electricity. Moreover, it deserves note that transmission expansion is not unique to wind: other generation sources will also require transmission expenditures, not surveyed here. Additionally, transmission expansion typically serves multiple purposes, and our approach to assigning the full costs of that expansion to generation capacity additions effectively ignores those other benefits. Finally, in some of the studies in our sample, transmission is purposefully oversized to allow for future generation expansion, leading to an overestimate of the transmission costs uniquely associated with the specific wind capacity additions. In general, the limitations in our methodology err towards an over-statement of the unit cost of transmission for wind.

Because the transmission costs surveyed here are, in some cases, sizable, and the range in cost estimates is broad, it is also of interest to understand how differences in study objectives, methodologies, tools, and assumptions can impact the resulting cost estimates. In particular, among the factors that are expected to impact the unit cost of transmission for wind are the amount of incremental generation studied and the transmission line voltage, the length of transmission, equipment cost assumptions, differences in study methodologies and objectives, and deviations in studies from inherent assumptions in our methodology. Though our review did not provide unambiguous answers to the importance of these various factors, and we are necessarily limited to our specific sample of studies, our general findings are as follows:

- Unit transmission costs of wind, among our sample, do not appear to increase significantly with higher levels of wind additions. Two effects may influence the unit cost of transmission as wind capacity increases: a supply curve effect where transmission costs increase as lower cost resources are accessed, and an economies of scale effect where transmission costs decrease as higher voltage lines are used to more efficiently access large resource areas. While our sample is not ideally suited for directly measuring either of these effects, we do not find that those studies that analyze large amounts of wind additions necessarily predict higher per-unit costs of transmission. In fact, the studies with the largest additions of wind energy tend to have relatively low unit costs of transmission, indicating that the economies of scale effect may contribute to lower costs among our study sample.

\footnotetext{
${ }^{1}$ In the early $2000 \mathrm{~s}$, the average cost of wind projects was roughly $\$ 1300 / \mathrm{kW}$. Using this average wind project cost for the denominator, the $\$ 300 / \mathrm{kW}$ median unit cost of transmission cost equates to $23 \%$ of the average wind project cost.
} 
- Unit transmission costs do not unambiguously increase in scenarios with increasing transmission length. Several studies with large quantities of new transmission investments across broad geographic regions had unit transmission costs that fell in the mid-range of our sample.

- Unit transmission costs do, however, appear to increase in scenarios that added long transmission lines and relatively little new generation. Studies found to have the highest unit costs of transmission often add long transmission lines without adding substantial amounts of new generation. The majority of the high unit cost scenarios were multi-state transmission lines designed to deliver all of the new generation added in the scenario from remote resource areas to distant load centers.

- Equipment cost assumptions vary widely across studies in our sample. These variations may be influenced by regional factors, when the study was conducted, and the level of detail used in the equipment cost estimates. These differences are likely to contribute to a portion of the variation in the unit costs of transmission across our sample.

Though the above factors are surely important, variations in study approaches and methodologies and the characteristics of the grid may be of similar if not greater importance. In particular, we find that transmission designed to accommodate the full nameplate capacity of all new generation during peak periods on sparsely interconnected transmission lines appears to have a higher cost than transmission designed to reduce congestion costs caused by new wind generation based on an economic dispatch of an interconnected transmission network. This finding may have implications for future transmission planning efforts oriented toward accessing additional wind energy.

Finally, we have compared the detailed bottom up transmission studies that are the subject of our review to three higher-level, top down studies. We find that the implied unit cost of transmission in two of these three studies is below or equivalent to the median cost in our sample of bottom up studies $(\$ 300 / \mathrm{kW})$. Specifically, two studies that evaluate transmission to enable a $20 \%$ wind energy scenario in the U.S., the AEP Interstate Transmission Vision and the NREL Wind Deployment System (WinDS), have a unit cost of transmission of $\$ 150$ - $\$ 300 / \mathrm{kW}$ and $\$ 207 / \mathrm{kW}$, respectively. Notably, the unit cost of transmission in these two top down studies compares favorably to the unit cost of transmission for wind implied in a recent bottom up study of a $20 \%$ wind energy scenario in the Eastern Interconnection, the Joint Coordinated System Plan (JCSP). The unit cost of transmission in the JCSP $20 \%$ wind energy scenario was $\$ 195 / \mathrm{kW}$. The wind capital cost adjustment factors and base transmission costs used in the National Energy Modeling System (NEMS) to reflect transmission costs and other factors, on the other hand, loosely imply an average unit transmission cost of $\$ 450 / \mathrm{kW}$ for $40 \mathrm{GW}$ of new wind by $2030,50 \%$ higher than our median estimate. More discussion of these findings can be found in the body of the report. 


\section{Introduction}

Wind power capacity additions are growing at a rapid pace in the United States (see, e.g., Wiser and Bolinger 2008). These additions are driven by federal tax incentives, state-level renewables portfolio standards, the rising cost of fossil-fuel generation, concerns about energy security and price volatility, and growing interest in reducing carbon dioxide emissions.

This rapid development, however, has been coupled with a growing concern that maintaining or increasing wind capacity additions will require substantial additions to the nation's transmission infrastructure (see, e.g., U.S. DOE 2006, 2008; Jacobs 2007; CDEAC 2006). ${ }^{2}$ A variety of barriers exist to new transmission development, and many studies have expressed concern that transmission investments in the United States are not keeping up with the need for those investments (Hirst 2004; Hirst and Kirby 2001b; NERC 2008; Joskow 2005a, b; U.S. DOE 2002, 2006).

Transmission is particularly important for wind power due to the unique characteristics of the wind resource and wind power projects (WIRES and CRA International 2008; National Grid 2006). Specifically, wind energy depends on wind resources that are sometimes located far from load centers, and wind development is therefore expected to increasingly rely on access to the bulk transmission system in order to move power from resource areas to load centers (U.S. DOE 2008; Vajjhala et al. 2008). Moreover, the total developable wind resource in an area to be served by new transmission is almost always larger that the size of an individual wind power project. As such, economies of scale in transmission investments dictate that it is more efficient to proactively build larger transmission ahead of wind generation rather than make smaller transmission investments for individual projects (Olsen 2007; CAISO 2006; Hirst and Kirby 2001a). Additionally, individual wind projects can be developed in a relatively short time period of two to three years, whereas large transmission facilities can take a decade to plan, permit, and construct. Finally, wind power projects rely on a variable resource and typically operate at capacity factors that range from $30 \%$ to over $40 \%$, ensuring that any transmission dedicated solely to wind generation will not be fully utilized for large portions of the year.

Various initiatives are underway to address the barriers that new transmission investment poses to renewable energy development specifically, and to address constraints to transmission expansion more broadly. The Federal Energy Regulatory Commission (FERC), for example, is currently working with transmission operators and stakeholders to reform the process for generators to interconnect with the bulk transmission system, called the interconnection queue (FERC 2008). FERC also recently issued FERC Order 890, requiring transmission operators to proactively participate in regional transmission planning processes including transmission development for economic, not just reliability, purposes (FERC 2007). In addition, under authority granted by the Energy Policy Act of 2005, the U.S. Department of Energy now has the ability to designate transmission constrained areas and FERC - under certain circumstances has the ability to support transmission investment in those areas. More generally, a growing number of state and regional entities are establishing policies and processes to proactively tackle

\footnotetext{
${ }^{2}$ Concern about the transmission needs associated with higher levels of wind penetration are not limited to the U.S. In fact, in addition to more-incremental transmission upgrades, very long-distance transmission solutions have been discussed in both Europe (Czisch and Giebel 2000) and China (Lew et al. 1998).
} 
the transmission barrier for renewable energy, through designation of renewable energy zones, creation of transmission infrastructure authorities, and other means (Wiser and Bolinger 2008; Porter and Fink 2008).

Though it is clear that institutional issues related to transmission planning, siting, and cost allocation will pose major obstacles to accelerated wind power deployment, also of concern is the potential cost of this infrastructure build out. Though it may be general knowledge that new transmission will be required for accelerated development of wind energy and that the initiatives noted above will reduce impediments to that transmission development, there is lesser understanding of how much that transmission will cost. Consequently, there is also little consensus on whether or not the cost of developing transmission will be a major barrier to the continued development of wind energy, or whether the institutional barriers to transmission expansion are likely to be of more immediate concern. ${ }^{3}$

Broadly, there are two ways to estimate the cost of transmission for wind power: top-down and bottom-up. A top-down approach is used in high-level studies like those that rely on the Energy Information Administration's (EIA) National Energy Modeling System (NEMS) and those that use the National Renewable Energy Laboratory's (NREL) Wind Deployment System (WinDS) model. Conceptual analyses are also sometimes included in more-academic studies of the feasibility of long-distance transmission for wind (see, e.g., Cavallo 2007; DeCarolis and Keith 2006; and Greenblatt et al. 2007). Though there are numerous advantages to these approaches, they do not incorporate detailed physical modeling of the transmission system, and therefore generate only coarse approximations for the transmission costs associated with increased wind power development. Alternatively, bottom-up transmission studies often include detailed physical modeling of the grid, and therefore will arguably produce more accurate estimates of the cost of transmission expansion if conducted appropriately. Recently, a number of bottom up transmission studies, ranging from very detailed to more conceptual, have included large amounts of new wind development. In comparison to a top-down model, these bottom-up studies examine specific transmission line paths and facility ratings. Detailed physical modeling of the transmission system, in the bottom-up studies that use it, also allows complex relationships between load, generation dispatch, power flows over parallel transmission paths, and reliability requirements to be incorporated into the analysis of transmission expansion requirements and costs.

In this report, we review a sample of 40 bottom-up transmission studies that have included wind power. ${ }^{4}$ These studies cover a broad geographic area, and were completed from 2001-2008. Our

\footnotetext{
${ }^{3}$ Our focus on the cost of transmission for wind energy does not address the issue of the allocation of transmission costs to particular wind projects. The allocation of costs may also be a barrier to continued development of wind energy but we group the allocation of costs into the institutional barriers and do not address the issue further in this report.

${ }^{4}$ In so doing, we broadly follow the approach used by Auer et al. (2004) and EWEA (2005), which summarized transmission cost studies from Europe, and concluded that the additional transmission expenditure for wind was likely to cost less than $\$ 6 / \mathrm{MWh}$ for up to $30 \%$ wind penetration. One key difference between our approach and the approach employed in these studies is that they examine only country-specific analyses of large-scale wind integration that are based on detailed load flow assessment. The studies in our sample, however, are much more diverse in objectives, scope, and methods. Additional work on the grid connection costs associated with renewable energy in Europe has been summarized in Swider et al. (2008), focusing on just interconnection costs.
} 
primary goal in reviewing these studies is to develop a better understanding of the transmission costs needed to access growing quantities of wind generation (we do not address the institutional barriers to transmission investment). In so doing, we present information that allows a deeper appreciation of the nature and magnitude of the transmission cost barrier for wind energy. A secondary goal is to better understand differences in transmission planning approaches in order to identify those methodologies that seem most able to estimate the incremental transmission costs associated with wind development. Finally, in addition to providing some insight to policymakers and others on the magnitude of the transmission barrier and to transmission planners conducing bottom-up transmission assessments for wind, we hope that the resulting dataset and discussion might be used to inform the assumptions, methods, and results of topdown assessment models. In achieving all of these objectives, however, we are cognizant that the methodologies employed by the studies in our sample are diverse, and that comparisons among the studies are more illustrative than definitive.

The remainder of the report is structured as follows. We begin in Section 2 by identifying the transmission plans in our sample and highlighting differences among those studies. In Section 3, we discuss our methodology for estimating the unit cost of transmission for wind from each of the studies in our sample, the inherent assumptions in our simplified methodology, and the resulting caveats on the use and interpretation of our results. Section 4 presents pertinent statistics for each study in our sample, and the key results of our meta-analysis on the unit cost of transmission for wind across all studies. In Section 5, we discuss some of the possible drivers for the wide variation in the unit cost of transmission for wind, while in Section 6 we compare the results of the bottom-up studies in our sample to pertinent results from a sample of relevant top-down models that include transmission estimates for wind. Conclusions are offered in Section 7. Appendix A provides brief descriptions of each of the individual studies included in our review. ${ }^{5}$

\footnotetext{
${ }^{5}$ Appendix A is a working document. It is available in draft form upon request.
} 


\section{Description of Transmission Studies}

\subsection{Study Sample}

The 40 transmission studies included in our sample all analyze proposed transmission upgrades that are expected to accommodate increased wind power generation. In our collection of studies, we largely selected only those that evaluate transmission requirements for multiple new wind plants with a combined capacity greater than $300 \mathrm{MW}$; we therefore excluded from our sample individual generator interconnection studies. In a few cases, we included studies where wind resource maps and wind developer interest shows significant potential for new wind generation, even when those studies did not explicitly and separately evaluate wind. ${ }^{6}$

The general location of the studies included in our sample is illustrated in Figure 1, while the study region, author, title, date, and brief description of the scenarios from which we collect statistics are presented in Table 1 (more information on the content of the studies is presented in Table 2, later). The 40 studies in our sample cover a broad geographic area, were completed from 2001-2008, ${ }^{7}$ and for those study-scenarios that specifically analyze wind power capacity, do so with wind additions that range from as little as $63 \mathrm{MW}^{8}$ to as much as $236 \mathrm{GW}$.

The remainder of this section explores the many variations among the studies in our sample, focusing on: the degree to which the study focuses on wind; the type of organization authoring the study and geographic scope of study; the framework for evaluating necessary transmission upgrades; the degree of network interconnectivity; and the level of study detail. In our description of these issues, we focus on those studies that are considerably different from one another; the majority of studies fall between extremes, and we do not attempt to categorize all studies along all dimensions.

\footnotetext{
${ }^{6}$ At the time of publication we were unable to find studies detailing the expected amount of new generation and transmission cost for a number of notable transmission lines. The Wyoming-Colorado Intertie or TOT-3 was not included because no cost estimates were publicly available at the time of publication. This line was evaluated as part of a bundle of transmission projects in the RMATS study, however. More recently, a Duke-AEP joint-venture called Pioneer Transmission LLC proposed to build a 240 mile $765 \mathrm{kV}$ line in a high wind region of Indiana at an approximate cost of \$1 billion; see FERC submittal 20081015-4004 in docket ER09-75-000 for full details. No specific quantity of expected new generation accessed by the line was found, though multiple references were found such as "over $3000 \mathrm{MW}$ of new wind" and "thousands of MW of new wind in the interconnection queue in the region". Assuming that the new transmission line is able to access 4,000 MW of new wind generation, the unit cost would be about $\$ 250 / \mathrm{kW}$. In addition, the Energy Gateway is a set of proposed transmission projects that would help serve renewable resource areas in and around Wyoming and load centers in the West. The project would add 1,900 miles of new transmission lines and would have a cost of $\$ 6$ billion; see http://www.pacificorp.com/energygateway for more details. No estimate was found, however, of the total amount of new generation that is expected to be accessed by this new transmission. Finally, the Southwest Intertie Project (SWIP) is a $500 \mathrm{kV}$ transmission line that, if built, will stretch 500 miles between southern Idaho and southern Nevada. A study, The Southwest Intertie Project: Assessment of Potential Benefits, identifies a scenario in which the transmission line would access 1,233 MW of new wind and $925 \mathrm{MW}$ of new geothermal. The study, however, does not identify the expected cost of the new transmission line. The study was completed in November 2008 by Energy Strategies, LLC and is available at http://www.swipos.com.

${ }_{8}^{7}$ No studies completed after December 2008 were included in our sample.

${ }^{8}$ The scenario with only $63 \mathrm{MW}$ of wind is from one of the eight scenarios in the SCE transmission ranking cost report. The scenario with the next smallest amount of wind is $329 \mathrm{MW}$ in the same SCE report.
} 


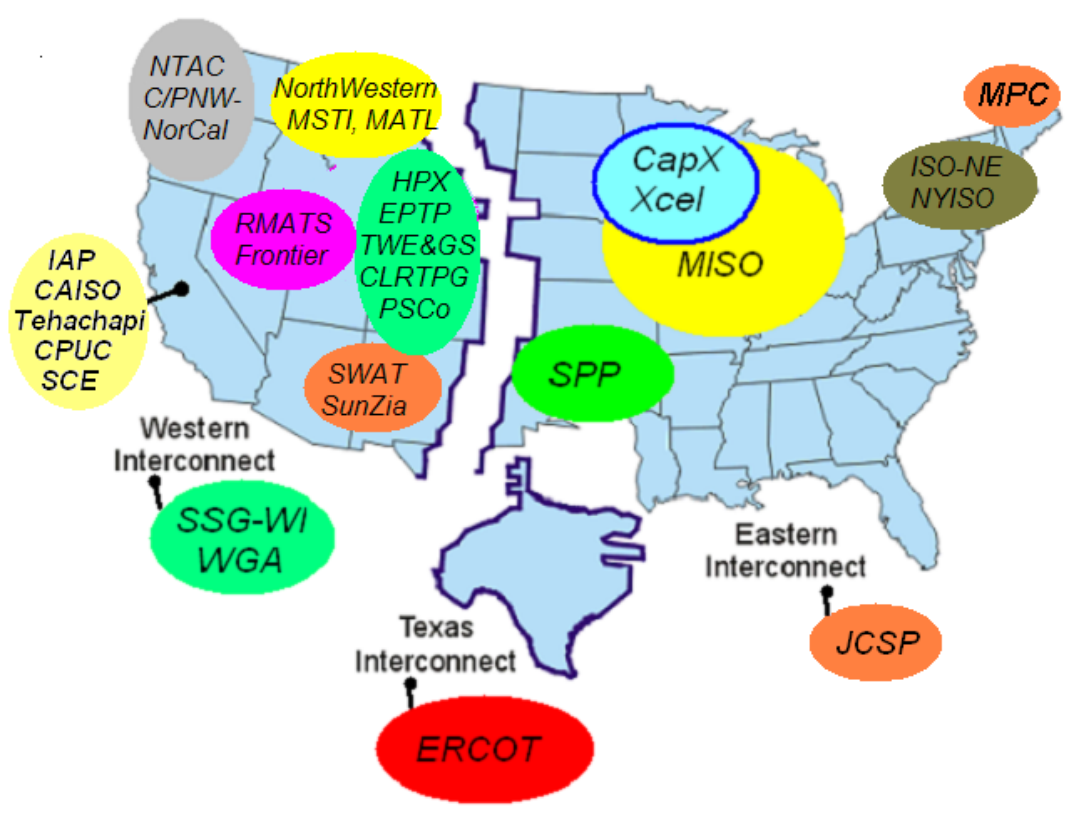

Figure 1. General Geographic Location of Transmission Studies in Sample

Table 1. Description of Studies Evaluated in Analysis

\begin{tabular}{|c|c|c|c|c|c|}
\hline Region & Principal Author & Date & Title of Study & $\begin{array}{c}\text { Study } \\
\text { Abbreviation }\end{array}$ & Scenario Description \\
\hline \multirow{17}{*}{ California } & \multirow{4}{*}{ California ISO (CAISO) } & \multirow{4}{*}{ August 2008} & \multirow{4}{*}{$\begin{array}{l}\text { Report on Preliminary Renewable } \\
\text { Transmission Plans }\end{array}$} & CAISO - A1 & New 500 kV substation into Southwest Powerlink Line \\
\hline & & & & CAISO - A2 & $\begin{array}{l}\text { Expand Midpoint Substation and construct third Midpoint- } \\
\text { Devers and new Devers - Mira Loma (or Valley) } 500 \mathrm{kV} \text { line }\end{array}$ \\
\hline & & & & CAISO - A4 & $\begin{array}{l}\text { Central California Clean Energy Transmission Project } \\
\text { (C3ETP) connection of renewable resources in the Kern } \\
\text { County area }\end{array}$ \\
\hline & & & & CAISO - A6 & $\begin{array}{l}\text { Construct a new } 500 \mathrm{kV} \text { location constrained resource } \\
\text { interconnection facility (LCRIF) to Kramer Jct. and Lugo } \\
\text { Substation }\end{array}$ \\
\hline & \multirow{2}{*}{$\begin{array}{l}\text { Intermittency Analysis Project } \\
\text { Team }\end{array}$} & \multirow[t]{2}{*}{ July 2007} & \multirow[t]{2}{*}{ Intermittency Analysis Project: Final Report } & & $201020 \%$ RPS target with 3 GW of new wind at Tehachap \\
\hline & & & & IAP - 2020 & $202033 \%$ RPS target \\
\hline & California ISO (CAISO) & December 2006 & $\begin{array}{l}\text { CAISO South Regional Transmission Plan for } \\
\text { 2006: Tehachapi Transmission Project }\end{array}$ & Tehachapi & 4.4 GW of new generation at Tehachapi Region \\
\hline & \multirow{8}{*}{$\begin{array}{l}\text { Southern California Edison } \\
\text { (SCE) }\end{array}$} & \multirow{8}{*}{ September 2007} & \multirow{8}{*}{$\begin{array}{l}\text { SCE Conceptual Transmission Requirements } \\
\text { and Costs for Integrating Renewable } \\
\text { Resources }\end{array}$} & SCE- LA/Kern & Los Angeles and Kern Counties (including Tehachapi) \\
\hline & & & & SCE - ISM - P & Inyo, San Bernardino, and Mono Counties, Pisgah \\
\hline & & & & SCE - ISM - EDM & $\begin{array}{l}\text { Inyo, San Bernardino, and Mono Counties, El } \\
\text { Dorado/Mohave }\end{array}$ \\
\hline & & & & SCE - ISM - MP & Inyo, San Bernardino, and Mono Counties, Mountain Pass \\
\hline & & & & SCE - ISM - V & Inyo, San Bernardino, and Mono Counties, Victorville \\
\hline & & & & SCE - ISM - K & Inyo, San Bernardino, and Mono Counties, Kramer \\
\hline & & & & SCE - ISM - I & Inyo, San Bernardino, and Mono Counties, Inyokern \\
\hline & & & & SCE - IR & Imperial and Riverside Counties, Clusters 9 and 10 \\
\hline & \multirow{2}{*}{$\begin{array}{c}\text { California Public Utility } \\
\text { Commission (CPUC) Energy } \\
\text { Division }\end{array}$} & \multirow{2}{*}{ December 2003} & \multirow{2}{*}{$\begin{array}{c}\text { Electric Transmission Plan for Renewable } \\
\text { Resources in California }\end{array}$} & CPUC - 2017 & $20 \%$ Renewables by 2017 as in original SB 1078 schedule \\
\hline & & & & CPUC - 2010 & $\begin{array}{c}20 \% \text { renewables by } 2010 \text { as proposed in Accelerated } \\
\text { Energy Action Plan }\end{array}$ \\
\hline $\begin{array}{c}\text { Eastern } \\
\text { Interconnection }\end{array}$ & Midwest ISO & December 2008 & $\begin{array}{c}\text { Joint System Coordianted Plan (JCSP): } \\
\text { Economic Assessment, Wrap-up Stakeholder } \\
\text { Meeting }\end{array}$ & JCSP & $20 \%$ Wind Energy Scenario \\
\hline
\end{tabular}


Table 1. Description of Studies Evaluated in Analysis (Continued)

\begin{tabular}{|c|c|c|c|c|c|}
\hline Region & Principal Author & Date & Title of Study & $\begin{array}{c}\text { Study } \\
\text { Abbreviation }\end{array}$ & Scenario Description \\
\hline \multirow{15}{*}{ Midwest } & CRA International & September 2008 & $\begin{array}{l}\text { First Two Loops of SPP EHV Overlay } \\
\text { Transmission Expansion }\end{array}$ & SPP-CRA & $\begin{array}{l}\text { First two loops of SPP EHV Overlay including Prarie Wind } \\
\text { and Tall Grass transmission projects (high cost estimate) }\end{array}$ \\
\hline & & & & SPP - OK - 2010N & 2010 Nominal Wind \\
\hline & Southwest Power Pool (SPP) & March 2008 & Oklahoma Electric Power Transmission Task & SPP - OK - 2020N & 2020 Nominal Wind \\
\hline & & & $\mathrm{Fo}$ & SPP - OK - 2010H & 2010 High Wind \\
\hline & & & & SPP - OK - $2020 \mathrm{H}$ & 2020 High Wind \\
\hline & Quanta Technology, LLC & March 2008 & $\begin{array}{c}\text { Southwest Power Pool (SPP) Updated EHV } \\
\text { Overlay Study }\end{array}$ & SPP - EHV & Midpoint Design 2: 765 kV EHV Overlay with Ozarks \\
\hline & Midwest ISO (MISO) & February 2007 & $\begin{array}{l}\text { Midwest ISO Transmission Expansion Plan } \\
\text { (MTEP) 2006: Vision Exploratory Study } \\
\text { (Section 7.4) }\end{array}$ & MISO '06 & 765 kV Network Overlay from Dakotas to Eastern Seaboard \\
\hline & CapX Utilities & January 2007 & $\begin{array}{l}\text { Community Based Energy Development } \\
\text { Transmission Study: West Central (MN) } \\
\text { Transmission Planning Zone }\end{array}$ & CapX - CBED & $\begin{array}{l}\text { Transmission needs in Central West Minnesota for } \\
\text { Community Energy Projects }\end{array}$ \\
\hline & Xcel Energy & June 2005 & $\begin{array}{l}\text { Buffalo Ridge Incremental Generation Outlet } \\
\text { Electric Transmission Study }\end{array}$ & Xcel - BRIGO & $\begin{array}{c}\text { Option } 31 \mathrm{~A} \text { is the preferred plan for additional generation } \\
\text { capacity at Buffalo Ridge }\end{array}$ \\
\hline & CapX Utilities & May 2005 & CapX 2020 Technical Update & & \\
\hline & & & & CapX - 2 & North/West bias Generation Scenario \\
\hline & Southwest Power Pool (SPP) & May 2005 & $\begin{array}{l}\text { Kansas/Panhandle Sub-Regional } \\
\text { Transmission Study }\end{array}$ & SPP - X & X-Plan or Plan A \\
\hline & Midwest ISO (MISO) & June 2003 & MISO MTEP 2003 & MISO '03 - 1 & lowa and S. Minnesota $345 \mathrm{kV}$ and Dakotas $500 \mathrm{kV}$ \\
\hline & & & & MISO '03 - 2 & Northwest $345 \mathrm{kV}$ Expansion and Dakotas $500 \mathrm{kV}$ \\
\hline & Xcel Energy & December 2001 & $\begin{array}{l}\text { Application for Certificates of Need for } \\
\text { Transmission Lines to Support the } \\
\text { Development of Wind Powered Generation in } \\
\text { Southwestern Minnesota }\end{array}$ & $\begin{array}{l}\text { Xcel - BR - Proj } \\
\text { Xcel - BR - Actual }\end{array}$ & $\begin{array}{l}\text { Option } 1 \text { to obtain 825MW of transmission capacity from } \\
\text { Buffalo Ridge - Projected } \\
\text { Actual Transmission Cost in } 2008 \text { (SEC 2008) }\end{array}$ \\
\hline \multirow{3}{*}{ Northeast } & $\begin{array}{l}\text { Maine Public Service and } \\
\text { Central Maine Power Company }\end{array}$ & July 2008 & $\begin{array}{c}\text { Request for Certificate of Public Convenience } \\
\text { and Necessity to Construct the Maine Power } \\
\text { Connection ("MPC") to Enable } \\
\text { Interconnection of Aroostook Wind Energy } \\
\text { Project. }\end{array}$ & MPC & Proposed Route from Northern to Southern Maine \\
\hline & ISO New England (ISO-NE) & August 2007 & $\begin{array}{l}\text { New England Electricity Scenario Analysis: } \\
\text { Exploring the economic, reliability, and } \\
\text { environmental impacts of various resource } \\
\text { outcomes for meeting the region's future } \\
\text { electricity needs }\end{array}$ & $\begin{array}{l}\text { ISO-NE - High } \\
\text { ISO-NE - Low }\end{array}$ & $\begin{array}{l}\text { Renewables scenario, high transmission cost estimate } \\
\text { Renewables scenario, low transmission cost estimate }\end{array}$ \\
\hline & $\begin{array}{l}\text { GE Power Systems Energy } \\
\text { Consulting }\end{array}$ & February 2004 & $\begin{array}{l}\text { The Effects of Integrating Wind Power on } \\
\text { Transmission System Planning, Reliability, } \\
\text { and Operations: Report on Phase } 1\end{array}$ & NYISO & $\begin{array}{l}\text { Incremental wind additions that are possible without new } \\
\text { transmission }\end{array}$ \\
\hline
\end{tabular}


Table 1. Description of Studies Evaluated in Analysis (Continued)

\begin{tabular}{|c|c|c|c|c|c|}
\hline Region & Principal Author & Date & Title of Study & $\begin{array}{c}\text { Study } \\
\text { Abbreviation }\end{array}$ & Scenario Description \\
\hline & & & & $\begin{array}{l}\text { ERCOT - TOS - } \\
\qquad 1 \mathrm{~A}\end{array}$ & $\begin{array}{c}5.2 \mathrm{GW} \text { of new wind in } 5 \mathrm{CREZs} \text { - least cost but less } \\
\text { expandable }\end{array}$ \\
\hline & & & & $\begin{array}{l}\text { ERCOT - TOS - } \\
1 \mathrm{~B}\end{array}$ & $\begin{array}{l}\text { 5.2 GW of new wind in } 5 \text { CREZs - easily expandable to } \\
\text { Scenario } 2\end{array}$ \\
\hline & $\begin{array}{l}\text { Electric Reliability Council of } \\
\text { Texas (ERCOT) }\end{array}$ & April 2008 & $\begin{array}{l}\text { Competitive Renewable Energy Zones } \\
\text { Transmission Optimization Study }\end{array}$ & ERCOT - TOS - 2 & $\begin{array}{c}\text { 11.6 GW of new wind in } 5 \text { CREZs - Scenario } 2 \text { selected for } \\
\text { development by PUCT }\end{array}$ \\
\hline & & & & ERCOT - TOS - 3 & 18.0 GW of new wind in 5 CREZs \\
\hline & & & & ERCOT - TOS - 4 & 17.5 GW of new wind in 4 CREZs (None in Panhandle B) \\
\hline \multirow[t]{9}{*}{ Texas } & Southwest Power Pool (SPP) & April 2007 & $\begin{array}{l}\text { SPP Transmission Expansion Supplement to } \\
\text { Support Development of Texas Panhandle } \\
\text { Competitive Renewable Energy Zones }\end{array}$ & SPP - 2 & 4.5 GW of new wind from Texas CREZ \\
\hline & Southwest Power Pool (SPP) & December 2006 & $\begin{array}{l}\text { Southwest Power Pool Inc's Analysis of } \\
\text { Transmission Alternatives for Competitive } \\
\text { Renewable Energy Zones in Texas }\end{array}$ & SPP -1 & $1.5 \mathrm{GW}$ of new wind from Texas CREZ \\
\hline & & & & ERCOT - C3 & $3 \mathrm{GW}$ of new wind in the Coast region \\
\hline & & & & ERCOT - CW3 & 3.8 GW of new wind in the Central Western Texas region \\
\hline & & & & ERCOT - M2 & 3.8 GW of new wind in the McCamey region \\
\hline & $\begin{array}{l}\text { Electric Reliability Council of } \\
\text { Texas (ERCOT) }\end{array}$ & December 2006 & $\begin{array}{l}\text { Analysis of Transmission Alternatives for } \\
\text { CREZs in Texas }\end{array}$ & ERCOT - P4 & 4.6 GW of new wind in the Panhandle region \\
\hline & & & & ERCOT - Cb1 & 3.3 GW of new wind in the Central and McCamey regions \\
\hline & & & & ERCOT - Cb2 & $4 \mathrm{GW}$ of new wind in the Central and McCamey regions \\
\hline & & & & ERCOT - Cb3 & $\begin{array}{c}5.3 \mathrm{GW} \text { of new wind in the Central, McCamey, and Coast } \\
\text { regions }\end{array}$ \\
\hline
\end{tabular}


Table 1. Description of Studies Evaluated in Analysis (Continued)

\begin{tabular}{|c|c|c|c|c|c|}
\hline Region & Principal Author & Date & Title of Study & $\begin{array}{c}\text { Study } \\
\text { Abbreviation }\end{array}$ & Scenario Description \\
\hline & HPX Participants & June 2008 & $\begin{array}{c}\text { High Plains Express Transmission Project: } \\
\text { Feasibility Study Report }\end{array}$ & $\mathrm{HPX}$ & $\begin{array}{l}\text { Renewables only (Wind with } 10 \% \text { overbuild and } 500 \mathrm{MW} \text { of } \\
\text { solar) }\end{array}$ \\
\hline & $\begin{array}{l}\text { K. R. Saline \& Assoc. (for } \\
\text { WestConnect) }\end{array}$ & January 2008 & $\begin{array}{l}\text { Western-RMR Transmission Plan 2008-2017: } \\
\text { Eastern Plains Transmission Project in } 2007 \\
\text { WestConnect Transmission Plan }\end{array}$ & EPTP - 2 & Holcomb Station to Green Valley Station \\
\hline & $\begin{array}{l}\text { K. R. Saline \& Assoc. (for } \\
\text { WestConnect) }\end{array}$ & January 2008 & $\begin{array}{c}\text { SunZia Transmission Plan 2008-2017 in } 2007 \\
\text { WestConnect Transmission Plan }\end{array}$ & SunZia & $500 \mathrm{kV}$ line from New Mexico to Arizona \\
\hline & $\begin{array}{l}\text { SWAT Renewable Energy } \\
\text { Task Force }\end{array}$ & January 2008 & $\begin{array}{l}\text { Southwest Area Transmission (SWAT) } \\
\text { Oversight Committee-Arizona Renewable } \\
\text { Transmission Task Force }\end{array}$ & SWAT & $\begin{array}{c}\text { Transmission to access renewable resource zones in } \\
\text { Arizona }\end{array}$ \\
\hline & $\begin{array}{l}\text { NorthWestern Energy Electric } \\
\text { Transmission Planning }\end{array}$ & January 2008 & $\begin{array}{l}\text { Mountain States Transmission Intertie (MSTI) } \\
\text { Phase } 1 \text { Comprehensive Progress Report } \\
\text { (Draft) and Open Season Update Meeting }\end{array}$ & MSTI & $500 \mathrm{kV}$ Midpoint to Townsend line \\
\hline & $\begin{array}{l}\text { Arizona Public Service, } \\
\text { PacifiCorp, National Grid, } \\
\text { Wyoming Infrastructure } \\
\text { Authority }\end{array}$ & January 2008 & $\begin{array}{l}\text { TransWest Express and Gateway South } \\
\text { Stakeholder Presentation January 23,2008 }\end{array}$ & TWE and GS & Reference Case \\
\hline & $\begin{array}{l}\text { Technical Analysis Committee } \\
\text { (PG\&E Chair) }\end{array}$ & November 2007 & $\begin{array}{l}\text { WECC Regional Planning Review } \\
\text { Canada/Pacific Northwest - Northern } \\
\text { California Transmission Line Project }\end{array}$ & C/PNW-NorCal & $\begin{array}{c}\text { Hybrid AC in the Northwest and DC to N. California with } \\
\text { high renewables (Case A) }\end{array}$ \\
\hline & $\begin{array}{l}\text { Western Regional } \\
\text { Transmission Expansion }\end{array}$ & April 2007 & $\begin{array}{l}\text { Western Regional Transmission Expansion } \\
\text { Partnership: Benefit-Cost Analysis of Frontier }\end{array}$ & Frontier - A & $\begin{array}{l}\text { 3.6 GW of new wind with transmission alternative } 7 \mathrm{~b}(500 \\
\qquad \mathrm{kV} \mathrm{AC} \mathrm{line} \mathrm{from} \mathrm{WY} \mathrm{to} \mathrm{So.} \mathrm{CA)}\end{array}$ \\
\hline & Partnership (WRTEP) & 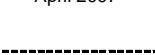 & Line Possibilities & Frontier - B & $\begin{array}{c}2.6 \mathrm{GW} \text { of new wind and } 1 \mathrm{GW} \text { of coal with transmission } \\
\text { alternative } 7 \mathrm{~b}\end{array}$ \\
\hline & $\begin{array}{l}\text { Montana Alberta Tie Ltd. } \\
\text { (MATL) }\end{array}$ & August 2006 & $\begin{array}{c}\text { Montana-Alberta Tie } 230 \mathrm{kV} \text { Transmission } \\
\text { Line: Transmission Development Facilities } \\
\text { Application Volume One }\end{array}$ & MATL & New $230 \mathrm{kV}$ line between Montana and Alberta \\
\hline \multirow[t]{12}{*}{ West } & $\begin{array}{l}\text { Colorado Long Range } \\
\text { Transmission Planning Group } \\
\text { (CLRTPG) }\end{array}$ & July 2006 & $\begin{array}{l}\text { Colorado Long Range Transmission Planning } \\
\text { Study 2005-2015 }\end{array}$ & CLRTPG - N1 & Northern Resource Scenario - Alternative 1 \\
\hline & \multirow{4}{*}{$\begin{array}{c}\text { Northwest Transmission } \\
\text { Assessment Committee } \\
\text { (NTAC) }\end{array}$} & \multirow{4}{*}{ May 2006} & \multirow{4}{*}{$\begin{array}{c}\text { Canada-Northwest-California Transmission } \\
\text { Options Study }\end{array}$} & NTAC - 1 & Submarine DC Cable: Prince Rupert to San Francisco \\
\hline & & & & NTAC - 2A' & AC lines from Vancouver Island to WA/OR border \\
\hline & & & & NTAC - $2 A$ & AC lines from Vancouver Island to Northern California \\
\hline & & & & NTAC - 2B & $\begin{array}{l}\text { AC lines from Vancouver Island to Northern California with } \\
\text { submarine DC from WA/OR border to San Francisco }\end{array}$ \\
\hline & $\begin{array}{l}\text { Xcel Energy Transmission } \\
\text { Planning }\end{array}$ & April 2006 & $\begin{array}{l}\text { Wind Integration Study Report Of Existing } \\
\text { and Potential } 2003 \text { Least Cost Resource Plan } \\
\text { Wind Generation }\end{array}$ & PSCo & Transmission impact of $775 \mathrm{MW}$ of new wind in Colorado \\
\hline & $\begin{array}{l}\text { Tri-state Generation and } \\
\text { Transmission and Western } \\
\text { Area Power Administration }\end{array}$ & March 2006 & $\begin{array}{l}\text { Preliminary Report: Eastern Plains } \\
\text { Transmission Project } 500 \mathrm{kV} \text { and } 345 \mathrm{kV} \\
\text { Comparison }\end{array}$ & EPTP - 1 & South Cases 500 kV Scenario 1800 MW \\
\hline & $\begin{array}{l}\text { Clean and Diversified Energy } \\
\text { Advisory Committee (CDEAC) } \\
\text { Transmission Task Force }\end{array}$ & March 2006 & $\begin{array}{l}\text { Report of the Transmission Task Force to the } \\
\text { Western Governors Association (WGA) }\end{array}$ & CDEAC & High Renewables Case \\
\hline & $\begin{array}{l}\text { NorthWestern Energy Electric } \\
\text { Transmission Planning }\end{array}$ & May 2005 & $\begin{array}{c}\text { Montana - Idaho Path Open Season Study } \\
\text { Report }\end{array}$ & NorthWestern & $\begin{array}{l}\text { System improvements to move } 700 \mathrm{MW} \text { from Eastern } \\
\text { area, } 800 \mathrm{MW} \text { from Great Falls area, and a total of } 1500 \\
\text { MW moved to Idaho }\end{array}$ \\
\hline & \multirow{2}{*}{ RMATS } & \multirow{2}{*}{ September 2004} & \multirow{2}{*}{$\begin{array}{l}\text { Rocky Mountain Area Transmission Study } \\
\text { (RMATS) }\end{array}$} & RMATS - 1 & Regional $345 \mathrm{kV}$ expansion with $3 \mathrm{GW}$ of new wind \\
\hline & & & & RMATS - 2 & $\begin{array}{l}\text { Regional } 345 \mathrm{kV} \text { expansion and long } 500 \mathrm{kV} \text { lines from } \mathrm{WY} \\
\text { to CA with } 5 \mathrm{GW} \text { of new wind }\end{array}$ \\
\hline & $\begin{array}{l}\text { Seams Steering Group of the } \\
\text { Western Interconnect (SSG- } \\
\text { WI) }\end{array}$ & October 2003 & $\begin{array}{l}\text { Framework for Expansion of the Western } \\
\text { Interconnection Transmission System }\end{array}$ & SSG - WI & High renewables case for 2013 \\
\hline
\end{tabular}

\subsection{Degree of Focus on Wind Energy}

A key distinguishing feature among the studies in our sample is the degree to which those studies focus on wind power in their analysis. On one extreme, a number of the studies were carried out with the express objective of determining the transmission investments and associated costs of accommodating increasing wind development. The Electric Reliability Council of Texas 
(ERCOT) and Southwest Power Pool (SPP) evaluations of competitive renewable energy zones (CREZs), for instance, estimated the cost of accommodating particular levels of incremental wind development in specific resource zones in Texas. These studies use wind production data to capture the particular characteristics of wind plants and to thereby determine the transmission investments required to accommodate more wind energy.

Studies like the CAISO assessment of transmission out of the Tehachapi area in California also focus on transmission in areas with large amounts of potential wind energy development, but in these cases the studies also include a limited amount of generation other than wind in the same region. Still other studies only evaluate renewable energy additions, but not with an exclusive focus on wind; examples in this latter category include the Intermittency Analysis Project and the CPUC Energy Division studies in California, and the SWAT Renewable Energy Task Force study in Arizona.

In contrast, a number of the studies in our sample include relatively small amounts of wind capacity compared to other forms of incremental generation capacity. As one example, the Midwest ISO (MISO) 2003 Transmission Expansion Plan based its assumed mix of incremental generation capacity on trends in the transmission interconnection queue at that time, and therefore included significant amounts of incremental gas and coal generation. Another particular aspect of this MISO study (as well as others) is that the various proposed transmission solutions were evaluated in the context of different projections for generation development, but the transmission evaluated in each scenario is by no means optimized for a particular amount of incremental wind development. At the extreme, still other studies do not specifically analyze wind capacity additions at all; we include such studies in our sample only when wind resource maps and wind developer interest shows the potential for new wind generation in the areas analyzed by the study.

Finally, in a number of the studies covering the Western U.S., the focus is not so much on determining the specific transmission investments required to accommodating projected generation development, but instead on studying specific transmission lines that would add transfer capacity across otherwise-constrained paths. The Frontier, High Plains Express, Transwest Express and Gateway South, SunZia, Montana-Alberta Tie Line, Mountain States Transmission Intertie, and the Canada/Pacific Northwest-Northern California line studies are all examples of studies that focus primarily on particular transmission lines rather than on wind generation per se. ${ }^{9}$

\subsection{Study Authorship and Geographic Scope}

Many of the larger regional studies in our sample were performed as part of the transmission planning process of Independent System Operators (ISOs) and Regional Transmission Organizations (RTOs); examples include the MISO '03, SPP-X, SPP-EHV, and Tehachapi studies. The Joint Coordinated System Plan (JCSP), a large regional transmission planning study covering the majority of the Eastern Interconnection, was performed by multiple ISOs and

\footnotetext{
${ }^{9}$ Another way to phrase this issue is that some studies ask the question: What transmission improvements are required if we add new generation to the transmission system? Other studies, however, ask the question: How much transfer capacity will be added between regions if we build a particular transmission line?
} 
RTOs. A number of large regional transmission planning studies have also been conducted in the Western U.S. The SSG-WI and CDEAC studies, for example, cover the entire Western Interconnection, whereas the NTAC, RMATS, and CLRTPG studies focus on multi-state subregions within the West. Outside of California, there are no ISOs or RTOs in the West, and in these instances large regional transmission planning studies have often been performed by stateled organizations or voluntary utility/transmission organizations. Studies of smaller-scale transmission investments were often performed by investor-owned utilities (IOUs) such as Xcel's study of Buffalo Ridge or the renewable transmission cost ranking reports performed by IOUs in California. ${ }^{10}$ Finally, a number of studies in our sample were performed for state energy planning or regulatory bodies such as the California CPUC report, the California Energy Commission's Intermittency Analysis Project, and the New York State Energy Research Development Authority's study of wind for the New York Independent System Operator (NYISO) footprint.

\subsection{General Framework: Congestion vs. Deliverability}

Another important difference among the studies is the general framework used to evaluate transmission investments. These frameworks can be classified into two loose categories: ${ }^{11,12}$

- Congestion focused: ${ }^{13}$ Transmission investments are made to economically reduce congestion (or system redispatch) costs that would be incurred with the addition of new generation.

- Deliverability focused: ${ }^{14}$ Transmission investments are made to increase the transmission capacity between generators and load under particular system conditions.

Though individual studies sometimes fall between these two categories, the primary difference between the two approaches is that one focuses on decreasing congestion while the other focuses on increasing transmission transfer capacity. As an extreme example, consider an existing

\footnotetext{
${ }^{10}$ We only include SCE's transmission ranking report in our sample. We do not include similar transmission ranking reports performed by PG\&E and SDG\&E because those reports do not include sufficient information to identify the cost of transmission for wind. PG\&E's study does not identify wind energy as a potential resource at any of the delivery points used in the study. SDG\&E's study includes the cost of building transmission from delivery points like the SONGS nuclear plant to load centers, but it does not include the transmission upgrades required to connect high-wind regions to delivery points such as SONGS.

${ }^{11}$ Hirst (2004) roughly splits general transmission planning studies from across the U.S. by the studies' focus on transmission to maintain reliability versus transmission to reduce congestion. In contrast, the studies in our sample generally focus on transmission to accommodate increased generation and roughly differ on the approach used to determine the amount of new transmission necessary to accommodate that generation.

${ }^{12}$ The authors of the JCSP study use similar distinctions in describing transmission planning approaches. Our use of "congestion focused" is similar to their use of "energy resource planning (production cost model)" and our use of "deliverability focused" is similar to their use of "traditional planning (powerflow)".

${ }^{13}$ Congestion in this report is generally meant to refer to the increase in production costs that occurs when generators are dispatched out-of-merit order due to security constraints. Lesieutre and Eto (2004) indicate that this definition of congestion cost is also commonly referred to as the system redispatch cost.

${ }^{14}$ Deliverability is a specific term in some transmission regions that refers to a type of study to ensure that the output of a generator can be delivered to the grid at all times and become a network resource to any load served by the transmission operator. We do not intend to be as specific with our use of this terminology, but the general concept is similar.
} 
transmission line that is fully utilized by a remote fossil-fuel power plant that is $\$ 1 / \mathrm{MWh}$ cheaper than a local fossil-fuel plant. In the deliverability focused approach, a new wind generator located near the remote fossil-fuel plant will require new transmission infrastructure with a transfer capability equivalent to the nameplate capacity of the wind project. In contrast, the congestion focused approach will allow the output of the wind generator to displace the power of the remote fossil-fuel generator, and new transmission might not be built unless the cost of expanding the transmission system is lower than the savings gained by accessing cheaper, remote fossil resources $(\$ 1 / \mathrm{MWh})$. As per this simple example, a deliverability focused approach can yield greater transmission expenditures than a congestion focused effort.

ERCOT performed an evaluation of several CREZs using a congestion focus, as follows:

- The base case included all expected transmission and generation additions in a future reference year.

- Transmission solutions were proposed that would relieve binding constraints that would otherwise force wind to be curtailed to an unacceptable level. The analysis involved a security constrained economic dispatch model of the entire system, using location-specific hourly wind data for existing and planned wind plants.

- Proposed transmission solutions were then evaluated in more detail using power flow and contingency models based on the system conditions when transmission constraints were binding. The transmission solutions were evaluated in an iterative manner such that the least cost solutions were selected to reach the target level of wind development in a region.

In contrast, deliverability focused studies tend to center on developing lines that can increase the transfer capability between specific new generators (or areas) and specific load centers, without necessarily taking congestion costs (and therefore redispatch opportunities) into account. Studies using this methodology are somewhat similar to those that are often used for evaluating singleproject interconnection and transmission service requests. Planners using this framework will typically evaluate in great detail one or more transmission power flow cases that include both the new generation and proposed transmission during particular loading conditions (generally during a peak load case). The planner will then ensure that all constraints are met during normal system operation and during plausible contingences. Detailed studies will ensure that voltage and stability criteria are met in addition to thermal limits of equipment. The Technical Analysis Committee of the Canada/ Pacific Northwest - Northern California Transmission Line Project performed an analysis of transmission options using this approach:

The purpose of this preliminary technical study is to demonstrate the feasibility of the project in accordance with NERC/WECC reliability standards.... The GE PSLF Version 16.0_11 Load Flow Program was used to perform the power flow studies. PG\&E's governor power flow routine was used to perform post transient power flow contingency analysis... The starting power flow base case used in this analysis is the WECC 2016 Heavy Summer Peak base case.... (PG\&E 2007a, p 20)

The motivation for deliverability focused studies is often not to determine the least-cost transmission investments required to economically access a certain amount of new generation, but instead to document the transmission investments necessary to add new transfer capacity 
over a path that lacks available capacity. ${ }^{15}$ In this respect, in a deliverability focused study the transmission investments may be the same regardless of the type of generation that ultimately uses the new transmission facilities. ${ }^{16}$

In deliverability focused studies that specifically include wind capacity additions, study authors generally assume that those wind facilities require transmission transfer capacity equivalent to the name-plate rating of the wind projects (e.g., 3,000 MW of new wind will require 3,000 MW of new transmission capacity) or evaluate a limited number of snapshot powerflow cases in which all wind is assumed to be producing at its full nameplate capacity. A minority of studies, however, assume that it is possible to 'overbuild' wind generation by adding, for instance, 3,600 MW of wind capacity and only 3,000 MW of transfer capacity on a new transmission path. Though such a strategy may entail some curtailment of wind output, the cost of that curtailment may be lower than the cost of fully building transmission to meet peak wind conditions during peak transmission usage periods, and the magnitude of curtailment may be small if projects are geographically dispersed (due to the benefits of geographic diversity in wind production). A congestion focused study can inherently accommodate a similar strategy by allowing wind power to be dispatched down or curtailed if transmission limits are binding in a security constrained economic dispatch. In ERCOT's CREZ analysis, for example, transmission planners only added transmission up to the point that wind plants were curtailed less than $2 \%$ of the year due to transmission limits.

A final potential difference between a congestion focused study and a deliverability focused study is that authors of a deliverability focused study pick the load center to which the new generation will be delivered. Transmission solutions will then be evaluated to enable the specified transaction. A congestion study, however, need not specify the destination of a particular amount of new generation. Instead, a security constrained economic dispatch model will optimize the dispatch of all generation in a region subject to the constraint that all loads must be met, without specifying required transactions between particular generators and loads. A security constrained economic dispatch of the Western Interconnection, for instance, will minimize the production costs of meeting all loads given transmission limits and available generation. Such a study might find that when additional wind capacity is added in Wyoming, generators in the Denver or Salt Lake City areas are the most economic option to dispatch down when the wind energy is available (essentially delivering Wyoming wind to the Denver or Salt Lake City loads). On the other hand, a deliverability focused study that intends to evaluate the transmission requirements for wind generation installed in Wyoming to meet California's

\footnotetext{
${ }^{15}$ The amount of new transmission capacity will be equivalent to the incremental generation additions possible with the transmission investment only in the case that no redispatch is used, that only one transmission path is available, and that all incremental generation requires long-term firm transmission capacity.

${ }_{16}$ Strbac et al. (2007) present a detailed analysis of the difference in transmission costs for wind and conventional resources in the U.K. They find that it is not efficient to invest in transmission in order to be able to accommodate the simultaneous peak outputs from both conventional and wind generation. They also conclude that wind generation tends to drive less transmission investment than conventional generation, particularly when there are opportunities for the sharing of transmission assets between different generation technologies. Sharing transmission between different generating technologies enables economic redispatch opportunities when the transmission capacity is a binding limit or wind to utilize a portion of a transmission line that is unused by the other generation technologies while the wind is blowing.
} 
renewables portfolio standard will only evaluate transmission to enable that particular transaction.

\subsection{Degree of Transmission Network Interconnectivity}

A number of the studies in our sample evaluate transmission upgrades as part of a highly connected electrical network. The transmission element that is upgraded or replaced may allow some amount of additional flow over that element, but by relieving a binding constraint, may also allow significantly more power to flow over other, parallel paths. In these situations, the additional generation that can be accommodated behind a now relieved transmission constraint may be greater than the transmission capacity of the element added in the upgrade.

In contrast, many new proposed transmission lines in the West are between regions that have little existing transmission transfer capacity. The proposed lines may be connected at various points to the existing network, but resemble long radial lines rather than upgrades to specific network elements. Examples of transmission proposals that resemble radial lines include many of the NTAC scenarios, the C/PNW-NorCal, and the Frontier line. The HPX and TWE \& GS lines also somewhat resemble long inter-regional radial lines, but they include various points where power is picked up or dropped off along the path. These situations are typically modeled with a deliverability focus. ${ }^{17}$

\subsection{Level of Detail}

All of the studies are conceptual to some degree in that they require forecasts of future system conditions to estimate the loading of the transmission system and future generation development. ${ }^{18}$ The level of detail used in the evaluation of transmission and resources, however, varies considerably. Transmission projects that are very close to construction, such as the CAISO study of the Tehachapi expansion and the Xcel BRIGO study, are nearly as detailed as studies used in interconnecting individual generators to the network. These very detailed studies will incorporate power-flow, contingency, and stability analyses to evaluate transmission lines. This more-detailed approach is also used in a number of studies to evaluate large, but conceptual, transmission lines such as the C/PNW-NorCal study by PG\&E. On the other hand, other studies of similar large, very conceptual transmission lines that resemble radial paths (e.g., the Frontier line study) often rely on less-detailed engineering judgment rather than on detailed electrical system modeling.

\subsection{Summary}

All of the studies in our sample address transmission investments that are likely to enable new wind generation. That similarity notwithstanding, the differences among the studies in scope, authorship, objectives, methodology, and planning tools are great. Though we recognize this diversity and are cognizant that comparisons among these studies are therefore somewhat

\footnotetext{
${ }^{17}$ Congestion management techniques such as redispacth are not available for a radial line with only one type of generation at the pick-up point.

${ }^{18}$ Even in the case that the actual cost of transmission lines is know from construction records, the determination of how much generation was built due to the additional transmission capacity added by a network line requires an analysis based on assumptions of how the system would have been operated if the transmission line were not built.
} 
inappropriate, we nonetheless emphasize such simple comparisons in this report. We do so in order to improve our understanding of the range of transmission costs needed to access greater quantities of wind, and to highlight some of the drivers of those costs. In so doing, we gloss over many important details and differences among the studies in our sample. 


\section{Methodology}

Our comparison of the studies focuses primarily on the unit cost of transmission required to access wind resources. Here we describe our simple methodology for estimating this cost, and some of the limitations of that methodology. These limitations are due to the fact that the data available from many of the transmission planning studies in our sample do not allow for a direct estimation of the actual transmission cost attributable to increasing wind generation. To elucidate this point, we begin by briefly describing what data would be needed for a direct and accurate determination of the transmission costs imposed by increased wind power development.

\subsection{An "Ideal" Study}

Ideally, studies would provide the total cost of transmission that is due solely to the addition of a specified amount of wind generation, above and beyond any transmission expenditures required in the event that that wind generation did not exist and that other generation resources were used to meet load. In such an ideal study, the amount of congestion and the level of electricity reliability would also be equivalent between the two scenarios, allowing for a precise and fair comparison of transmission expenditures. In this instance, one could readily and accurately estimate the additional unit cost of transmission for wind by dividing the total cost of incremental transmission in the high wind scenario by the incremental amount of wind added in that scenario.

The transmission studies in our sample rarely meet these idealized requirements, in part because the purpose of these studies is not to uniquely estimate the incremental transmission costs associated with wind. In particular, with few exceptions, these studies do not estimate the cost of transmission that is exactly due to a particular amount of incremental generation added to the system, while keeping projected electricity reliability and congestion equal to what they would have been if the new generation and associated transmission were not added to the system. The Joint Coordinated System Plan (JCSP) in the Eastern Interconnection and the ERCOT CREZ analyses are rare examples of studies that come close to replicating an ideal study for determining the cost of transmission specifically for new wind. In many other studies, however, transmission is built to offset pending reliability concerns, relieve pre-existing congestion, or is sized so that other generation can be added to the network aside from just wind. In these instances, it is not possible to precisely estimate the incremental costs uniquely associated with new wind power additions.

\subsection{Simplified Approach}

At the risk of over-simplification, but with the benefit of analytic simplicity, we largely ignore these complexities in our comparison of the studies (though we do come back to some of these issues in the subsequent discussion of our results). Our approach is to collect statistics on the aggregate cost of the proposed transmission upgrades evaluated in the study, as well as the nameplate capacity of incremental generator additions accessed by those transmission investments (as identified in the study itself). Where multiple scenarios are evaluated, we focus on those with higher levels of wind penetration. If readily and publicly available, we also collect information on the mileage and voltage of transmission lines added in the study, as well as the 
assumed cost per mile of different transmission configurations. The transmission plans in our sample often do not clearly state all of the various statistics sought for the present report, however, requiring in many instances a degree of judgment to gather relevant statistics. The exact values presented in this report should therefore be taken with all due caution.

To loosely compare the studies based on the estimated unit cost of transmission for wind while also ignoring the many complexities associated with such simple comparisons, we use two units, one based on the nameplate rating of wind generation $(\$ / \mathrm{kW}$-wind) and the other based on projected wind-generated electricity (\$/MWh-wind). ${ }^{19}$ In those transmission studies in which wind is the only incremental generation added, we calculate the unit cost of transmission for wind in $\$ / \mathrm{kW}$-wind terms by simply dividing the aggregate cost of the proposed transmission upgrades evaluated by the study by the nameplate capacity of the incremental wind. We then calculate the unit cost in $\$ / \mathrm{MWh}$-wind terms by levelizing the transmission cost and dividing that figure by the amount of annual energy production expected from the new wind additions. For this report, the levelizing factor was assumed to be a constant $15 \%$ per year for all transmission lines and the capacity factor of wind was assumed to be $35 \%$ for all wind plants. ${ }^{20}$ The dollar value varies widely across studies. Many studies do not clearly state whether the results are in nominal or constant dollars and if in constant dollars, for which year. As such, for this study we simply assume that all cost figures are reported in nominal, non-discounted dollars and report the data as provided by the study authors. ${ }^{21}$

These metrics are more difficult to calculate when a transmission study evaluates not just wind additions, but the addition of multiple generation types (e.g., wind, solar, gas, and coal). In these cases, it is typically impossible to specifically isolate the transmission costs uniquely associated with wind. Instead, we must simply assign a share of the additional transmission costs to all of the incremental generation. We do so based on a capacity weighting. ${ }^{22}$ On a capacity-weighted

\footnotetext{
${ }^{19}$ Numerous reviewers suggested that we compare the transmission cost on a $\$ / \mathrm{MW}$-mi basis, as this is a commonly used parameter to characterize transmission costs. The MW in the denominator of this term, however, refers to the MW of transmission transfer capacity of the transmission line - a term that is not often presented in studies. The MW that we collect and present in this study, on the other hand, refers to the nameplate capacity of new generation additions. The purpose of this study is not to estimate the equipment cost of transmission per se, but rather to estimate the transmission cost associated with the addition of new additions of generation capacity. Based on the studies we evaluate, a $\$ / \mathrm{MW}$-mi term calculated using the MW of nameplate generation capacity often leads to a nonsensical value vis-á-vis typical \$/MW-mi values calculated using the MW of transfer capacity of transmission lines.

${ }^{20}$ The capacity factors of wind plants will vary by region according to the quality of the wind resource. We use a single point estimate of a $35 \%$ capacity factor for all studies, however, because not all studies present an assumed capacity factor of wind plants in the transmission study.

${ }^{21}$ We could have tried to correct this by assuming, for instance, that all costs were reported in constant dollars for the year in which the study was completed. But, over the full range of years in which the studies were completed (2001-2008) the GDP deflator was approximately 19\%, though actual transmission costs may have escalated over this period at a rate greater than the GDP deflator. Commodity prices, a substantial portion of the cost of building new transmission, increased a rate considerably greater then the GDP deflator from 2001 to mid-2008 then began to decline at the end of 2008. The potential inaccuracy introduced by reporting all values in nominal dollars is therefore far overwhelmed by other factors affecting the estimate of the unit cost of transmission for wind. The ratio of the maximum to minimum unit cost of transmission for wind between all studies completed just in 2008, for example, is over $730 \%$.

${ }^{22}$ Another plausible approach is to allocate costs on an energy-weighted basis. On an energy-weighted basis, the unit cost of transmission for wind in $\$ / \mathrm{kW}$-wind terms assumes that incremental generation capacity imposes
} 
basis, the unit cost of transmission for wind in $\$ / \mathrm{kW}$-wind terms is estimated by simply dividing the total transmission cost in a study by the total amount of incremental generation capacity (wind and non-wind) modeled in that study. In so doing, this metric assumes that within any individual study all incremental generation capacity imposes transmission costs in proportion to its nameplate capacity rating. Capacity weighting also reflects the fact that firm reservations on transmission lines are typically based on capacity, and that a new power plant will often reserve its full nameplate capacity on a transmission path over which it plans to move power. We calculate the capacity-weighted unit cost of transmission for wind in $\$ / M W h-w i n d$ terms in the same way as described previously.

\subsection{Limitations}

Because our methodology, and the studies themselves, differ from the ideal scenario described earlier, our estimates of the unit cost of transmission for wind are imprecise, and comparability among studies is imperfect. In addition those limitations mentioned earlier, four additional important limitations deserve specific mention. ${ }^{23}$

First, in a study where, for example, new coal plants and new wind plants are co-located, meaning that the same transmission facilities can be used by both generator types, our methodology should provide an upper bound for the cost that is attributable to wind. If, however, the study adds remote wind and new gas plants near load centers, but does not separate the responsibility of transmission investments between wind and gas, then our methodology will incorrectly assume that both generator types are responsible for the incremental transmission costs in proportion to their nameplate capacity. In these instances, our methodology will likely understate the cost of transmission attributable to wind.

Second, our methodology assigns all additional transmission costs to new electricity generators, and thereby implicitly assumes that the only beneficiaries of the new transmission investments are those generators. In contrast, the transmission studies in our sample sometimes indicate that the proposed transmission investments will not only accommodate increased generation but will also offset planned reliability-based investments or relieve pre-existing transmission congestion. In these cases, our methodology overstates the transmission costs that are attributable to all new electricity generators, including wind.

Third, for our methodology to correctly estimate the unit cost of transmission for wind, the new transmission embedded in each study must exactly match that which is necessary to serve the amount of incremental generation added by the study. In reality, however, some of the studies in

\footnotetext{
transmission costs in proportion to expected electricity generation, and is therefore calculated by allocating total transmission costs between wind and non-wind resources in proportion to expected electricity production. In a study that adds both wind and coal, for example, the energy-weighted methodology assigns more responsibility for the cost of the upgrade to coal, due to its higher capacity factor, than would be assigned if costs were assigned based on nameplate capacity. In theory, at least, a wind plant could use hourly non-firm transmission contracts to approach an energy based transmission charge (Stoft et al. 1997). We explored this option but did not find the results to be particularly illuminating, so we do not repeat the energy-weighted results in this paper.

${ }^{23}$ Again, our study does not address the issue of cost allocation, and the unit cost of transmission for wind reported in this study does not imply that new wind generation projects will actually be responsible for paying these full costs.
} 
our sample present transmission expansion plans that make a specified generation scenario feasible, but those transmission investments are not necessarily optimal or sized exactly to the specified amount of incremental generation. Lumpiness and economies of scale in transmission investments suggest that it is better to oversize lines than to try to size them exactly for forecasted needs (Hirst and Kirby 2001a), and a number of studies appear to present scenarios in which transmission capacity exceeds what is necessary to accommodate the new generation contemplated by the study's authors. By assigning the full cost of this new transmission to the new generators specified by such studies, our methodology will tend to overstate the cost of transmission attributable to all new generators, including wind.

Finally, our methodology assumes that the transmission investments analyzed by each study do not displace transmission that would need to be built in a reference future without the new wind. In other words, the aggregate additional transmission expenditure is assumed to be incremental to a reference case in which the wind additions did not occur. If, on the other hand, wind is not built in future years, then other resources may need to be added that also impose transmission costs. By assuming that these costs are not "avoidable" by the specified wind additions, and by instead attributing the full cost of new transmission to the new generation in that scenario, we overstate the incremental cost of transmission attributable to wind.

Because of these limitations our methodology best captures the additional cost of transmission attributable to wind when faced with radial lines to remote regions to access generation resources that are co-located. Our methodology is not as well suited to cases where new transmission is part of a well connected network that provides congestion relief, reliability benefits, and access to a wide variety of resources, not all of which require new transmission. The results of our analysis should therefore be interpreted and used with care. Despite the important limitations noted here, however, we do believe that the overall comparisons made in this report can improve our understanding of the range of transmission costs needed to access greater quantities of wind, and to highlight some of the drivers of those costs. We provide further information on the extent and impact of these limitations in a later section. 


\section{Results}

\subsection{Overview}

Key data collected from each of the 40 transmission planning studies, and where appropriate their multiple study scenarios, are summarized in Table 2. In particular, the amount of incremental wind power capacity (and total capacity) analyzed in the study is listed, along with the total cost of the associated transmission upgrades. A few studies do not specify what fraction of aggregate generation additions come from wind; these are indicated by blank cells in the "Incremental Wind Analyzed" column. The table also lists the primary voltages and total length of new transmission investments built in the specific study scenario, where those data are available.

Table 2. Summary of New Generation Capacity and Cost in Each Transmission Planning Study

\begin{tabular}{|c|c|c|c|c|c|c|c|}
\hline Region & Principal Author & Study Abbreviation & $\begin{array}{c}\text { Incremental } \\
\text { Wind Analyzed } \\
\text { (GW) }\end{array}$ & $\begin{array}{l}\text { Total Incremental } \\
\text { Generation } \\
\text { Analyzed (GW) }\end{array}$ & $\begin{array}{l}\text { Total Transmission } \\
\text { Cost (\$ Billion) }\end{array}$ & $\begin{array}{l}\text { Length of New } \\
\text { Transmission (mi) }\end{array}$ & $\begin{array}{c}\text { Primary Voltage of New } \\
\text { Transmission Lines (AC } \\
\text { Unless Noted) }\end{array}$ \\
\hline & & CAISO - A1 & 1.1 & 1.1 & $\$ 0.30$ & Not Applicable & $500 \mathrm{kV}$ \\
\hline & & CAISO - A2 & 0.5 & 2.9 & $\$ 1.50$ & 180 & $500 \mathrm{kV}$ \\
\hline & California ISO (CAISO) & & & & & & \\
\hline & & CAISO - A4 & 1.3 & 1.3 & $\$ 1.60$ & - & $500 \mathrm{kV}$ \\
\hline & & CAISO - A6 & 1.2 & 1.2 & $\$ 0.65$ & - & $500 \mathrm{kV}$ \\
\hline & & IAP - 2010T & 5.4 & 10.9 & $\$ 1.36$ & 300 & 500 and $230 \mathrm{kV}$ \\
\hline & Intermittency Analysis Project Team & & & & & & \\
\hline & & IAP - 2020 & 10.6 & 26.1 & $\$ 6.36$ & 1,470 & 500 and $230 \mathrm{kV}$ \\
\hline & California ISO (CAISO) & Tehachapi & 3.6 & 4.3 & $\$ 1.80$ & 249 & $\begin{array}{l}500 \mathrm{kV} \text { initially operated at } \\
230 \mathrm{kV}\end{array}$ \\
\hline & & SCE- LA/Kern & 5.4 & 7.7 & $\$ 2.61$ & 352 & 500 and $230 \mathrm{kV}$ \\
\hline \multirow[t]{10}{*}{ California } & & SCE - ISM - P & 0.6 & 6.5 & $\$ 1.55$ & 195 & $500 \mathrm{kV}$ \\
\hline & & SCE - ISM - EDM & 1.9 & 4.9 & $\$ 1.90$ & 235 & $500 \mathrm{kV}$ \\
\hline & & SCE - ISM - MP & 0.1 & 1.2 & $\$ 0.11$ & 52 & $230 \mathrm{kV}$ \\
\hline & Southern California Edison (SCE) & & & & & & \\
\hline & & SCE - ISM - V & 0.3 & 0.3 & $\$ 0.07$ & 11 & $230 \mathrm{kV}$ \\
\hline & & SCE - ISM - K & 0.9 & 4.7 & $\$ 0.75$ & - & 500 and $230 \mathrm{kV}$ \\
\hline & & SCE - ISM - I & 0.8 & 0.8 & $\$ 0.25$ & - & $230 \mathrm{kV}$ \\
\hline & & SCE - IR & 2.6 & 8.8 & $\$ 2.67$ & 300 & 500 and $230 \mathrm{kV}$ \\
\hline & California Public Utility Commission & CPUC - 2017 & 6.4 & 8.0 & $\$ 1.80$ & 1,500 & 500 and $230 \mathrm{kV}$ \\
\hline & & CPUC - 2010 & 6.4 & 8.0 & $\$ 1.91$ & 1,926 & 500 and $230 \mathrm{kV}$ \\
\hline $\begin{array}{c}\text { Eastern } \\
\text { Interconnection }\end{array}$ & Midwest ISO & JCSP & 236.0 & 403.1 & $\$ 78.58$ & 14,937 & $765 \mathrm{kV}$ and $800 \mathrm{kV} \mathrm{HVDC}$ \\
\hline
\end{tabular}

Note: Total transmission cost is reported in nominal dollars from various years 
Table 2. Summary of New Generation Capacity and Cost in Each Transmission Planning Study (Continued)

\begin{tabular}{|c|c|c|c|c|c|c|c|}
\hline Region & Principal Author & Study Abbreviation & $\begin{array}{c}\text { Incremental } \\
\text { Wind Analyzed } \\
\text { (GW) }\end{array}$ & $\begin{array}{l}\text { Total Incremental } \\
\text { Generation } \\
\text { Analyzed (GW) }\end{array}$ & $\begin{array}{l}\text { Total Transmission } \\
\text { Cost (\$ Billion) }\end{array}$ & $\begin{array}{l}\text { Length of New } \\
\text { Transmission (mi) }\end{array}$ & $\begin{array}{c}\text { Primary Voltage of New } \\
\text { Transmission Lines (AC } \\
\text { Unless Noted) }\end{array}$ \\
\hline \multirow{20}{*}{ Midwest } & CRA International & SPP-CRA & 14.0 & 18.5 & $\$ 3.40$ & 1,200 & $765 \mathrm{kV}$ \\
\hline & & SPP - OK - 2010N & 3.5 & 3.5 & $\$ 2.08$ & - & $345 \mathrm{kV}$ \\
\hline & & SPP - OK - 2020N & 7.0 & 7.0 & $\$ 3.17$ & - & $345 \mathrm{kV}$ \\
\hline & Southwest Power Pool (SPP) & & & & & & \\
\hline & & SPP - OK - $2010 \mathrm{H}$ & 4.5 & 4.5 & $\$ 2.50$ & - & $345 \mathrm{kV}$ \\
\hline & & SPP - OK - $2020 \mathrm{H}$ & 11.0 & 11.0 & $\$ 4.54$ & - & $345 \mathrm{kV}$ \\
\hline & Quanta Technology, LLC & SPP - EHV & 20.7 & 23.0 & $\$ 7.89$ & 4,073 & 765,500 , and $345 \mathrm{kV}$ \\
\hline & Midwest ISO (MISO) & MISO '06 & 16.0 & 16.0 & $\$ 31.00$ & 5,725 & $765 \mathrm{kV}$ \\
\hline & CapX Utilities & CapX - CBED & 3.5 & 3.5 & $\$ 0.38$ & 799 & $\begin{array}{c}345 \mathrm{kV}, 230 \mathrm{kV} \text {, and } 115 \\
\mathrm{kV}\end{array}$ \\
\hline & Xcel Energy & Xcel - BRIGO & 0.5 & 0.5 & $\$ 0.03$ & 101 & $115 \mathrm{kV}$ \\
\hline & & CapX - 1 & 2.3 & 6.3 & $\$ 1.41$ & 1,885 & $345 \mathrm{kV}$ \\
\hline & CapX Utilities & & & & & & \\
\hline & & CapX - 2 & 2.3 & 6.3 & $\$ 1.51$ & 2,007 & $345 \mathrm{kV}$ \\
\hline & Southwest Power Pool (SPP) & SPP - X & 2.5 & 3.1 & $\$ 0.46$ & 834 & $345 \mathrm{kV}$ \\
\hline & & MISO '03 - 1 & 10.0 & 48.3 & $\$ 0.66$ & 1,053 & 500 and $345 \mathrm{kV}$ \\
\hline & Midwest ISO (MISO) & & & & & & \\
\hline & & MISO '03 - 2 & 10.0 & 48.3 & $\$ 1.89$ & 2,420 & 500 and $345 \mathrm{kV}$ \\
\hline & & Xcel - BR - Proj & 0.8 & 0.8 & $\$ 0.16$ & 384 & 345 and $115 \mathrm{kV}$ \\
\hline & Xcel Energy & & & & & & \\
\hline & & Xcel - BR - Actual & 0.8 & 0.8 & $\$ 0.23$ & - & 345 and $115 \mathrm{kV}$ \\
\hline \multirow{5}{*}{ Northeast } & $\begin{array}{c}\text { Maine Public Service and Central Maine } \\
\text { Power Company }\end{array}$ & MPC & 0.8 & 0.8 & $\$ 0.63$ & 199 & $345 \mathrm{kV}$ \\
\hline & & ISO-NE - High & 6.8 & 6.8 & $\$ 3.90$ & - & - \\
\hline & ISO New England (ISO-NE) & & & & & & \\
\hline & & ISO-NE - Low & 6.8 & 6.8 & $\$ 0.58$ & - & - \\
\hline & GE Power Systems Energy Consulting & NYISO & 4.9 & 4.9 & $\$ 0.00$ & Not Applicable & - \\
\hline
\end{tabular}

Note: Total transmission cost is reported in nominal dollars from various years 
Table 2. Summary of New Generation Capacity and Cost in Each Transmission Planning Study (Continued)

\begin{tabular}{|c|c|c|c|c|c|c|c|}
\hline Region & Principal Author & Study Abbreviation & $\begin{array}{c}\text { Incremental } \\
\text { Wind Analyzed } \\
\text { (GW) }\end{array}$ & $\begin{array}{l}\text { Total Incremental } \\
\text { Generation } \\
\text { Analyzed (GW) }\end{array}$ & $\begin{array}{l}\text { Total Transmission } \\
\text { Cost (\$ Billion) }\end{array}$ & $\begin{array}{l}\text { Length of New } \\
\text { Transmission (mi) }\end{array}$ & $\begin{array}{c}\text { Primary Voltage of New } \\
\text { Transmission Lines (AC } \\
\text { Unless Noted) }\end{array}$ \\
\hline \multirow{14}{*}{ Texas } & & ERCOT - TOS - $1 \mathrm{~A}$ & 5.2 & 5.2 & $\$ 2.95$ & 1,638 & 138 and $345 \mathrm{kV}$ \\
\hline & & ERCOT - TOS - 1B & 5.2 & 5.2 & $\$ 3.78$ & 1,831 & $345 \mathrm{kV}$ \\
\hline & $\begin{array}{l}\text { Electric Reliability Council of Texas } \\
\text { (ERCOT) }\end{array}$ & ERCOT - TOS - 2 & 11.6 & 11.6 & $\$ 4.93$ & 2,376 & $345 \mathrm{kV}$ \\
\hline & & ERCOT - TOS - 3 & 18.0 & 18.0 & $\$ 6.38$ & 3,036 & $345 \mathrm{kV}$ and HVDC \\
\hline & & ERCOT - TOS - 4 & 17.5 & 17.5 & $\$ 5.75$ & 2,489 & $345 \mathrm{kV}$ and HVDC \\
\hline & Southwest Power Pool (SPP) & SPP - 2 & 4.5 & 4.5 & $\$ 1.13$ & 625 & $345 \mathrm{kV}$ \\
\hline & Southwest Power Pool (SPP) & SPP - 1 & 1.5 & 1.5 & $\$ 0.19$ & 170 & $345 \mathrm{kV}$ \\
\hline & & ERCOT - C3 & 3.0 & 3.0 & $\$ 0.32$ & 230 & $345 \mathrm{kV}$ \\
\hline & & ERCOT - CW3 & 3.8 & 3.8 & $\$ 0.96$ & 862 & $345 \mathrm{kV}$ \\
\hline & & ERCOT - M2 & 3.8 & 3.8 & $\$ 0.86$ & 650 & $345 \mathrm{kV}$ \\
\hline & $\begin{array}{l}\text { Electric Reliability Council of Texas } \\
\text { (ERCOT) }\end{array}$ & ERCOT - P4 & 4.6 & 4.6 & $\$ 1.52$ & 770 & $345 \mathrm{kV}$ \\
\hline & & ERCOT - Cb1 & 3.3 & 3.3 & $\$ 0.86$ & - & $345 \mathrm{kV}$ \\
\hline & & ERCOT - Cb2 & 4.0 & 4.0 & $\$ 1.16$ & - & $345 \mathrm{kV}$ \\
\hline & & ERCOT - Cb3 & 5.3 & 5.3 & $\$ 0.94$ & - & $345 \mathrm{kV}$ \\
\hline
\end{tabular}

Note: Total transmission cost is reported in nominal dollars from various years 
Table 2. Summary of New Generation Capacity and Cost in Each Transmission Planning Study (Continued)

\begin{tabular}{|c|c|c|c|c|c|c|c|}
\hline Region & Principal Author & Study Abbreviation & $\begin{array}{c}\text { Incremental } \\
\text { Wind Analyzed } \\
\text { (GW) }\end{array}$ & $\begin{array}{l}\text { Total Incremental } \\
\text { Generation } \\
\text { Analyzed (GW) }\end{array}$ & $\begin{array}{l}\text { Total Transmission } \\
\text { Cost (\$ Billion) }\end{array}$ & $\begin{array}{l}\text { Length of New } \\
\text { Transmission (mi) }\end{array}$ & $\begin{array}{c}\text { Primary Voltage of New } \\
\text { Transmission Lines (AC } \\
\text { Unless Noted) }\end{array}$ \\
\hline & HPX Participants & HPX & 3.3 & 3.8 & $\$ 5.13$ & 2,560 & $500 \mathrm{kV}$ \\
\hline & K. R. Saline \& Assoc. (for WestConnect) & EPTP - 2 & - & 2.4 & $\$ 1.50$ & 987 & 500 and $230 \mathrm{kV}$ \\
\hline & K. R. Saline \& Assoc. (for WestConnect) & SunZia & - & 1.5 & $\$ 0.80$ & 350 & $500 \mathrm{kV}$ \\
\hline & SWAT Renewable Energy Task Force & SWAT & 3.1 & 7.8 & $\$ 1.67$ & - & 500 and $230 \mathrm{kV}$ \\
\hline & $\begin{array}{l}\text { NorthWestern Energy Electric } \\
\text { Transmission Planning }\end{array}$ & MSTI & - & 1.5 & $\$ 0.72$ & 460 & $500 \mathrm{kV}$ \\
\hline & $\begin{array}{l}\text { Arizona Public Service, PacifiCorp, } \\
\text { National Grid, Wyoming Infrastructure } \\
\text { Authority }\end{array}$ & TWE and GS & 2.3 & 6.0 & $\$ 5.97$ & 2,125 & $500 \mathrm{kV}$ and HVDC \\
\hline & $\begin{array}{l}\text { Technical Analysis Committee (PG\&E } \\
\text { Chair) }\end{array}$ & C/PNW-NorCal & 3.6 & 3.6 & $\$ 5.00$ & 950 & $500 \mathrm{kV}$ and HVDC \\
\hline & Western Regional Transmission & Frontier - A & 3.6 & 3.6 & $\$ 4.30$ & 1,092 & $500 \mathrm{kV}$ \\
\hline & Expansion Partnership (WRTEP) & Frontier - B & 2.6 & 3.6 & $\$ 4.30$ & 1,092 & $500 \mathrm{kV}$ \\
\hline & Montana Alberta Tie Ltd. (MATL) & MATL & - & 0.6 & $\$ 0.12$ & 216 & $230 \mathrm{kV}$ \\
\hline & $\begin{array}{l}\text { Colorado Long Range Transmission } \\
\text { Planning Group (CLRTPG) }\end{array}$ & CLRTPG - N1 & 0.7 & 3.6 & $\$ 1.47$ & - & 345 and $230 \mathrm{kV}$ \\
\hline \multirow[t]{11}{*}{ West } & & NTAC - 1 & 3.2 & 4.0 & $\$ 6.43$ & 1,849 & $500 \mathrm{kV}$ (Submarine HVDC) \\
\hline & Northwest Transmission Assessment & NTAC - 2A' & 1.1 & 1.8 & $\$ 0.86$ & 600 & $230 \mathrm{kV}$ \\
\hline & Committee (N|AC) & NTAC - $2 A$ & 1.1 & 2.2 & $\$ 2.21$ & 1,269 & 500 and $230 \mathrm{kV}$ \\
\hline & & NTAC - 2B & 1.1 & 2.3 & $\$ 2.58$ & 1,255 & $\begin{array}{l}500 \text { (includes Submarine } \\
\text { HVDC) and } 230 \mathrm{kV}\end{array}$ \\
\hline & Xcel Energy Transmission Planning & PSCo & 0.8 & 0.8 & $\$ 0.00$ & Not Applicable & - \\
\hline & $\begin{array}{l}\text { Tri-state Generation and Transmission } \\
\text { and Western Area Power Administration }\end{array}$ & EPTP - 1 & - & 1.8 & $\$ 0.79$ & 820 & 500 and $230 \mathrm{kV}$ \\
\hline & $\begin{array}{c}\text { Clean and Diversified Energy Advisory } \\
\text { Committee (CDEAC) Transmission Task } \\
\text { Force }\end{array}$ & CDEAC & 25.5 & 42.8 & $\$ 6.79$ & 3,578 & $500 \mathrm{kV}$ \\
\hline & $\begin{array}{l}\text { NorthWestern Energy Electric } \\
\text { Transmission Planning }\end{array}$ & NorthWestern & - & 1.5 & $\$ 1.03$ & 513 & 500 and $230 \mathrm{kV}$ \\
\hline & DMMTS & RMATS - 1 & 3.0 & 6.3 & $\$ 0.97$ & 971 & $345 \mathrm{kV}$ \\
\hline & & RMATS - 2 & 5.0 & 11.8 & $\$ 4.27$ & 3,834 & $500 \mathrm{kV}$ \\
\hline & $\begin{array}{l}\text { Seams Steering Group of the Western } \\
\text { Interconnect (SSG-WI) }\end{array}$ & SSG - WI & 18.5 & 34.3 & $\$ 6.71$ & 3,360 & $500 \mathrm{kV}$ \\
\hline
\end{tabular}

Note: Total transmission cost is reported in nominal dollars from various years

\subsection{Implied Unit Cost of Transmission for Wind}

Using the data presented in Table 2, the implied unit cost of transmission for wind can be calculated as described in Section 3 of this report. In particular, the unit cost of transmission for wind in $\$ / \mathrm{kW}$-wind terms on a capacity-weighted basis is simply calculated by dividing the total transmission investment by the total amount of incremental generation capacity (wind and nonwind).

The resulting unit cost of transmission for wind, in $\$ / \mathrm{kW}$-wind terms, for our sample of studies is shown in Figure 2, sorted by increasing unit costs. ${ }^{24}$ The total amount of incremental wind capacity analyzed by each study scenario ("wind analyzed"), or the total incremental capacity in

\footnotetext{
${ }^{24}$ The MISO '06 study is not included in this or later graphics nor in the calculation of the median unit cost, for
} reasons discussed in Section 5. 
cases when it is not clear what portion of the new capacity is wind ("total analyzed"), is illustrated on the top axis of the figure.

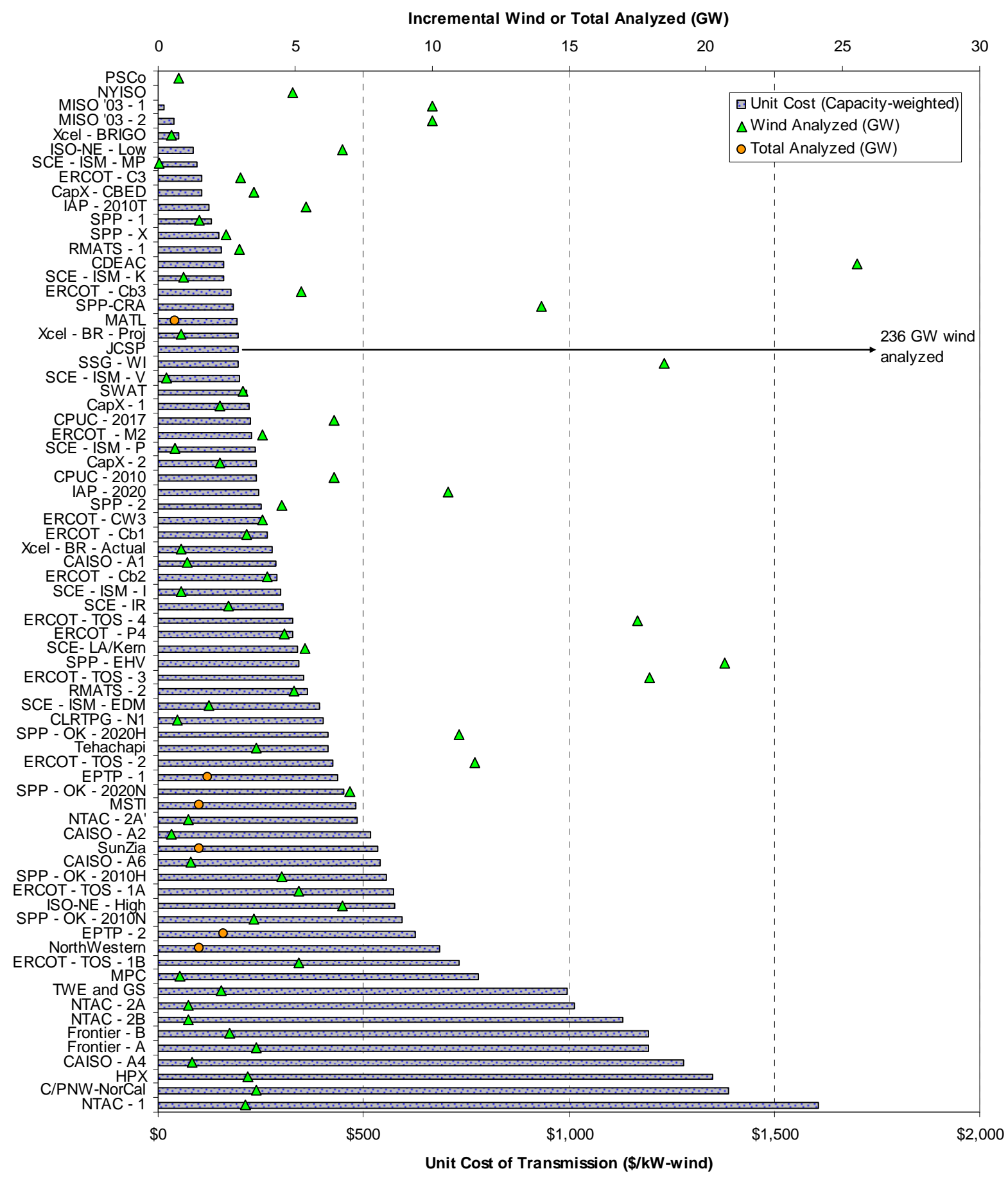

Note: Unit cost of transmission in nominal dollars from various years

Figure 2. Unit Cost of Transmission for Wind in $\$ / \mathrm{kW}$-wind Terms 
Though the limitations of our approach to calculating these costs should not be ignored, it is evident that the total range in unit transmission costs for wind implicit in these studies is vast ranging from $\$ 0 / \mathrm{kW}$ to over $\$ 1,500 / \mathrm{kW}$, based on our methodology. The majority of studies, however, have a unit cost of transmission that is below $\$ 500 / \mathrm{kW}$, or roughly $25 \%$ of the current $\$ 2,000 / \mathrm{kW}$ cost of building a new wind project. The median unit cost of transmission for wind (capacity-weighted) from all scenarios in our sample is $\$ 300 / \mathrm{kW}$, roughly $15 \%$ of the current cost of building a new wind project. ${ }^{25}$

The unit cost of transmission for wind in \$/MWh-wind terms was calculated by assuming a uniform capacity factor for wind across all studies. Though capacity factors may, in fact, range from below $30 \%$ to over $40 \%$, these details are typically not presented in transmission planning studies; as such, we use a single capacity factor of 35\% across all studies. Because of this, the resulting unit cost of transmission for wind in $\$ / \mathrm{MWh}$ terms, shown in Figure 3, is simply a scaled version of Figure $2 .^{26}$

As shown in Figure 3, the unit cost of transmission for wind in $\$ / \mathrm{MWh}$ terms is below $\$ 25 / \mathrm{MWh}$ in the majority of study scenarios. The median cost of transmission (capacity-weighted) from all scenarios is $\$ 15 / \mathrm{MWh}$. These figures compare to recent busbar wind power prices that range from $\$ 35 / \mathrm{MWh}$ to as high as $\$ 65 / \mathrm{MWh}$ with an average of $\$ 45 / \mathrm{MWh}$ (Wiser and Bolinger 2008). ${ }^{27}$ As such, the median unit cost of transmission, as estimated here, represents a cost adder of roughly $33 \%$ to the busbar price of wind, in most instances. The overall range in the unit transmission cost of wind is again vast, however, with a range of $\$ 0 / \mathrm{MWh}$ to as high as \$79/MWh. ${ }^{28}$

\footnotetext{
${ }^{25}$ In the early $2000 \mathrm{~s}$, the average cost of wind projects was roughly $\$ 1300 / \mathrm{kW}$. Using this average wind project cost for the denominator, the $\$ 300 / \mathrm{kW}$ median unit cost of transmission cost equates to $23 \%$ of the average wind project cost.

${ }^{26}$ It should be noted that a number of the studies in our sample evaluate transmission specifically designed to access wind resources with capacity factors that exceed $35 \%$. In these instances, the resulting unit cost in $\$ / \mathrm{MWh}$ terms presented in Figure 3 will over-state actual transmission expenditures. The unit cost in $\$ / \mathrm{kW}$ terms on a capacityweighted basis is independent of the capacity factor of wind, so that unit best represents the actual assumptions used in the transmission studies in our sample.

${ }^{27}$ The wind power price is the capacity-weighted average sale price for wind projects built in 2007. Prices include the production tax credit (PTC). If the federal PTC was not available the range would increase to between approximately $\$ 50 / \mathrm{MWh}$ and $\$ 85 / \mathrm{MWh}$ with an average of roughly $\$ 65 / \mathrm{MWh}$. If the average wind price without the PTC were used in the denominator, then the median transmission cost would be approximately $23 \%$ of the average wind price.

${ }^{28}$ The higher end of these transmission costs are startlingly higher than the \$6/MWh cost of transmission for wind found in numerous European studies for wind power penetrations up to 30\% (EWEA 2005).
} 


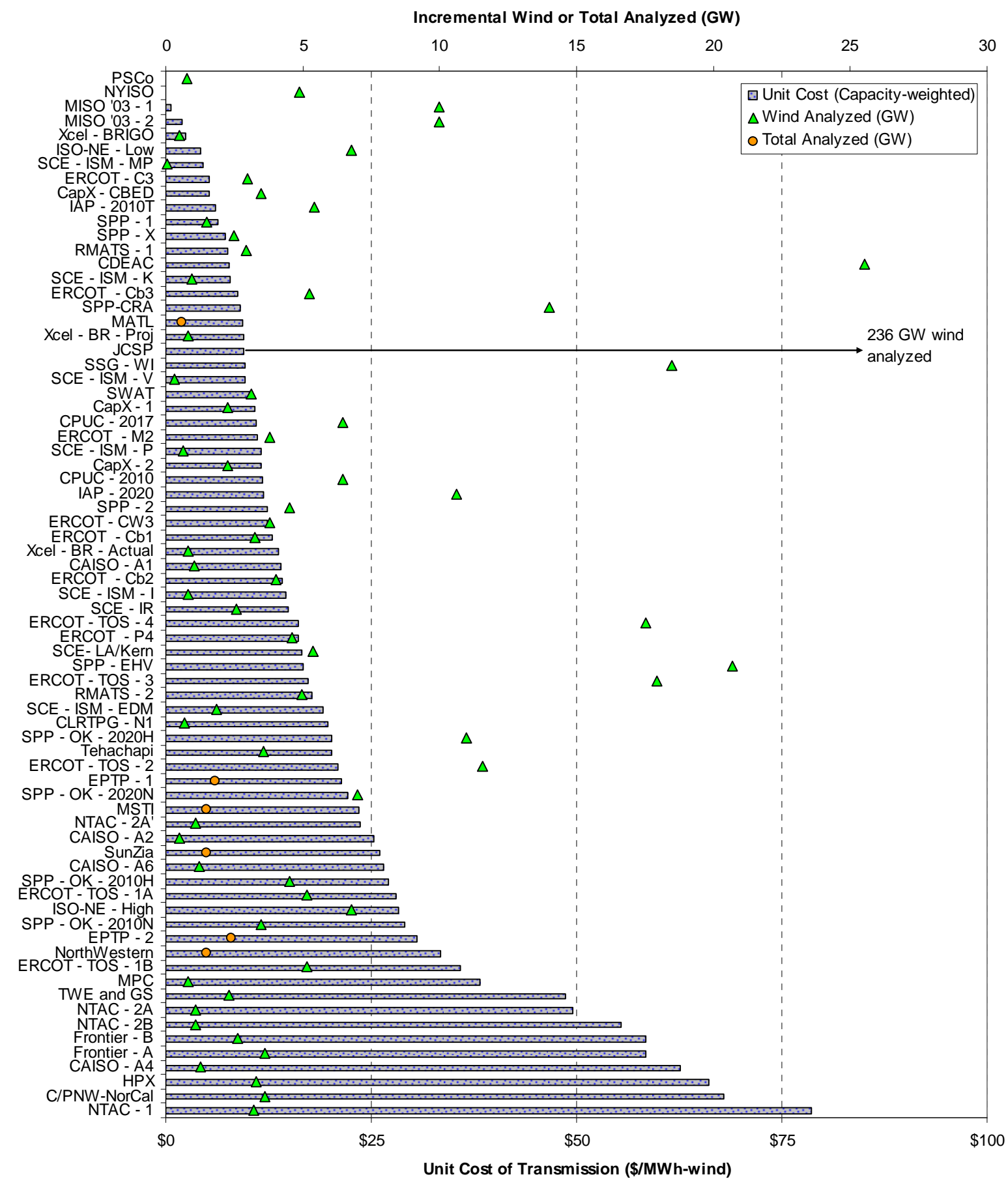

Note: (1) Unit cost of transmission in nominal dollars from various years

(2) Transmission cost levelized using $15 \%$ per year levelizing factor

(3) Energy produced by wind plants calculated assuming 35\% capacity factor for all scenarios

Figure 3. Unit Cost of Transmission for Wind in \$/MWh-wind Terms 


\subsection{Effect of Methodological Limitations}

Our estimates of the cost of transmission for wind, based on our sample, are complicated by the limitations of our methodology, as described in Section 3.3. These limitations ensure that, for any individual study, our estimate of the implied unit cost of transmission for wind may be either biased upwards or downwards. Here we provide specific examples of how these limitations might impact our results, and suggest that these limitations as a whole likely lead us to overstate the unit cost of transmission for wind.

\subsubsection{Shared Responsibility for New Transmission Lines}

As discussed previously, if a transmission study adds wind in remote areas and new gas plants near load centers, but does not separate the responsibility for transmission investments between wind and gas, then our methodology will incorrectly assume that both generator types are equally-responsible for the incremental transmission costs. In so doing, we will understate the cost of transmission attributable to wind.

For the 36 study scenarios in our sample that only evaluate wind power additions, this issue is moot. For the remaining 38 study scenarios, at least 18 locate all of the generation resources in the same basic region and an additional 12 add generation resources that are not located near wind but appear to be far from the load centers they are intended to serve. In these instances, our assumption of equal transmission cost allocation (on a capacity-weighted basis) appears reasonable.

In the remaining 8 scenarios, our assumption of equal responsibility is questionable due to significant new generation that is likely to be considerably closer to loads (e.g. natural gas plants) than wind and other resource types. Of these 8 scenarios, only one, the JCSP, provides sufficient data to directly evaluate any potential understatement of costs. As discussed later in Text Box 2, however, factors aside from the assumption of equal allocation of costs dominate the unit costs of transmission in the JCSP study which prevents us from understating the unit cost of transmission for wind in that study. The remaining 7 scenarios that are inconsistent with our assumption of shared responsibility for all new transmission are: CapX-2020-1 and -2, MISO '03-1 and -2, NTAC-2A and -2B, and SSG-WI. Though the transmission added in these scenarios likely benefits all new generation additions, wind (and other remote generation) probably drives a disproportionate share of the transmission upgrades, and our earlier estimate of the unit cost of transmission for wind likely understates actual costs in these instances.

In the extreme, if one assumes that new natural gas plants in these 7 scenarios impose no added transmission costs, but that all other resource types (e.g., wind, coal, and small hydro) are equally responsible on a capacity-weighted basis, then the implied unit cost of transmission for wind would increase for these 7 scenarios as indicated in Table 3. As shown, with this extreme assumption, the implied unit cost of transmission for wind in a given scenario increases by $22 \%$ to $265 \%$. The median unit cost of transmission for wind across all studies, previously reported at $\$ 300 / \mathrm{kW}$, increases to $\$ 330 / \mathrm{kW}$ if one uses the revised figures for the seven scenarios shown in Table 3. Based on these calculations, at least, it seems that this particular limitation to our methodology has little effect on the overall results presented here, though it does impact the results of several individual scenarios. 
Table 3. Impact of Assumption of Shared Responsibility on the Unit Cost of Transmission

\begin{tabular}{lccc} 
& \multicolumn{2}{c}{ Unit Cost of Transmission $\mathbf{( \$ \mathbf { k W } \text { , capacity-weighted) }}$} & \\
\cline { 2 - 4 } Scenario & $\begin{array}{c}\text { Assuming Shared } \\
\text { Responsibility }\end{array}$ & $\begin{array}{c}\text { Assuming No Responsibility for } \\
\text { Natural Gas Plants }\end{array}$ & $\begin{array}{c}\text { Potential Percent Increase in } \\
\text { Unit Transmission Cost }\end{array}$ \\
\hline MISO '03 - & $\$ 14$ & $\$ 50$ & $265 \%$ \\
MISO '03 - 2 & $\$ 39$ & $\$ 143$ & $265 \%$ \\
\hline SSG - WI & $\$ 196$ & $\$ 271$ & $38 \%$ \\
\hline CapX-1 & $\$ 222$ & $\$ 430$ & $93 \%$ \\
CapX - 2 & $\$ 238$ & $\$ 460$ & $93 \%$ \\
\hline NTAC - 2A & $\$ 1,014$ & $\$ 1,242$ & $22 \%$ \\
NTAC - 2B & $\$ 1,132$ & $\$ 1,449$ & $28 \%$ \\
\hline \hline Median Across & $\$ 300$ & $\$ 330$ & $10 \%$ \\
All Studies & &
\end{tabular}

\subsubsection{Incremental Generation as Only Beneficiary of New Transmission}

As also noted earlier, our methodology assigns all additional transmission costs to new electricity generators, and thereby effectively assumes that the only beneficiaries of the new transmission investments are those generators. In reality, however, studies frequently point to the additional reliability benefits and congestion relief that new transmission will provide. In these cases, our methodology overstates the transmission costs that are attributable specifically to wind.

As one example, in the Tehachapi study, the total cost of transmission to connect $4.4 \mathrm{GW}$ of incremental generation was estimated at $\$ 1.8$ billion. Our methodology implicitly assumes that this cost is solely attributable to the new incremental generation. The study, however, indicates that the transmission upgrades will allow the deferment of otherwise planned reliability upgrades, leading to a clear overstatement of the unit cost of transmission for wind using our methods.

Another example is the Maine Power Connection line (MPC) to interconnect $800 \mathrm{MW}$ of new wind generation in northern Maine. The northern region of Maine is electrically isolated from the southern part of Maine, and a transmission line connecting the two regions would offer reliability and economic advantages to customers in Maine. A $138 \mathrm{kV}$ transmission line was found to be sufficient to electrically connect the two regions, but such a line would not be sufficient to both electrically connect the two regions and allow the interconnection of $800 \mathrm{MW}$ of new wind generation in northern Maine. The MPC transmission plan, therefore, is a $345 \mathrm{kV}$ transmission line that will both allow the installation of $800 \mathrm{MW}$ of new wind and the interconnection of the two regions. Our methodology assigns the full cost of the transmission line to the wind plant without taking into account the other benefits of the transmission line. The same is likely the case in a number of the other studies in our sample, resulting in an overestimate of the unit cost of transmission for wind as presented in this report. 


\subsubsection{Transmission Exactly Sized to Meet Generation Additions}

Another implicit assumption in our methodology is that new transmission is sized to exactly the size required by the incremental generation added in a particular scenario. In reality, this is not always the case. In one of the ERCOT scenarios (ERCOT-TOS-1B), for example, the proposed transmission is designed so that it can not only accommodate the specified amount of wind additions, but also so that the system can be further expanded in the future to accommodate more wind at less cost than might otherwise be the case.

A more extreme example of transmission not being sized to the amount of incremental generation additions is a study called the "Vision Exploratory Study" that was part of the MISO transmission expansion plan for 2006. In that assessment, a $765 \mathrm{kV}$ network overlay between the Dakotas and the Eastern Seaboard was proposed along with $16 \mathrm{GW}$ of incremental wind capacity. Further analysis of the details behind this study, however, revealed that the transmission proposed in the scenario was substantially oversized for the amount of added generation. As a result, this scenario is excluded from the graphics presented earlier and the calculation of the median unit cost of transmission, though we discuss the approach and results of the study in Text Box 1.

Among our study sample as a whole, it is not entirely clear how sizable an effect the mismatch of transmission size and incremental generation might have. Nonetheless, by assigning the full cost of new transmission to the new generators specified by such studies, our methodology will tend to overstate the unit cost of transmission uniquely attributable to wind. 


\section{Text Box 1. Midwest ISO Transmission Expansion Plan (MTEP) 2006: Vision}

Exploratory Study (Section 7.4)

The MISO '06 study examined a transmission expansion plan in conjunction with the addition of $16 \mathrm{GW}$ of wind in the Midwest. The transmission proposed in the study consisted of a network overlay of 5,725 miles of $765 \mathrm{kV}$ lines that stretched between the Western regions of the Midwest to the PJM footprint on the Eastern Seaboard. The total cost was reported as $\$ 31$ billion, or $\$ 1,938 / \mathrm{kW}$-wind based on our simplified methodology.

The MISO '06 study used a security constrained economic dispatch model to identify constraints in the transmission system. Instead of iteratively expanding the transmission system to relieve binding constraints in a least cost manner, however, the MISO '06 study proposed a single transmission solution that would eliminate all pre-existing binding transmission constraints, even before the addition of $16 \mathrm{GW}$ of wind capacity (Osborn and Wilson 2007).

The transmission added in the MISO '06 plan was therefore not built solely to meet the needs of $16 \mathrm{GW}$ of additional wind capacity, but also to relieve pre-existing congestion between the Midwest and Eastern markets. Even when the $16 \mathrm{GW}$ of wind was added to the system, the maximum predicted flow on many paths was much less than 4,000 MW, the typical thermal capacity of a $765 \mathrm{kV}$ line (see Figure 4). In fact, the maximum flow on many of the $765 \mathrm{kV}$ paths is less than 2,000 MW and even $900 \mathrm{MW}$, the typical thermal capacity of $500 \mathrm{kV}$ and $345 \mathrm{kV}$ lines, respectively. Though the study authors recommend that those lines that do not require the full transfer capacity of a $765 \mathrm{kV}$ upgrade be removed, iteration of the design is left to future studies.
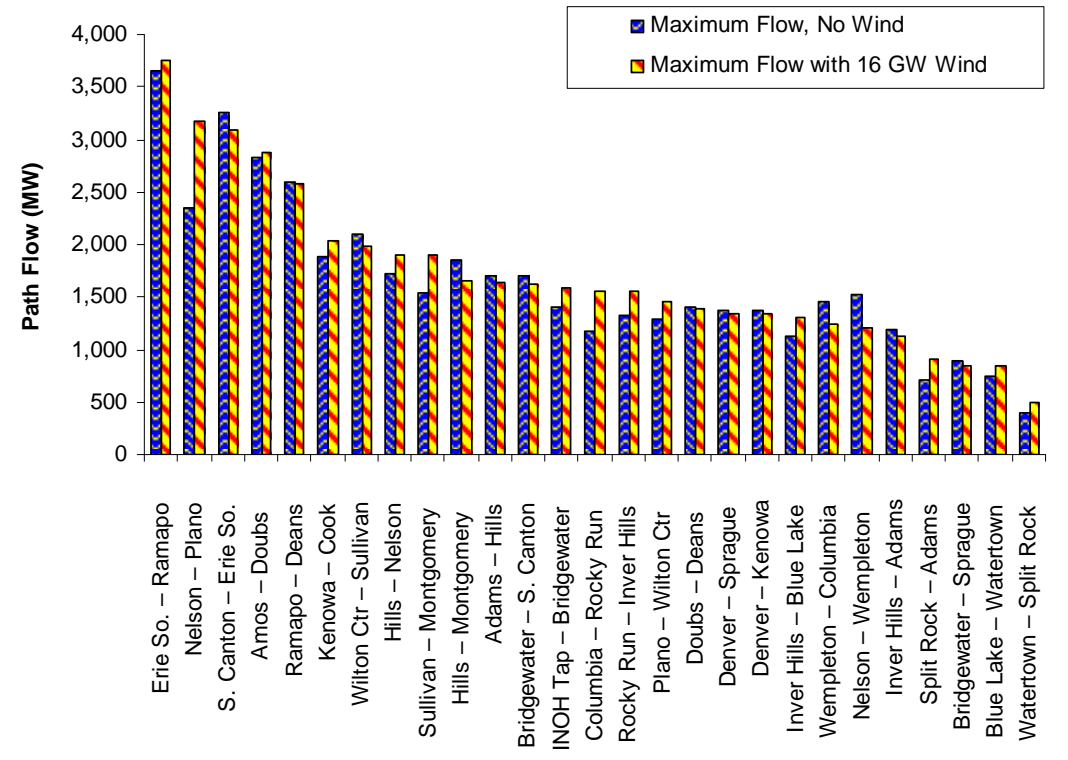

New 765 kV Path Name

Figure 4. Maximum Power Flow on 27 New $765 \mathrm{kV}$ Paths With and Without 16 GW of New Wind Generation in the MISO '06 Study (MISO 2007) 


\subsubsection{Reference Future Requires No Transmission}

Our methodology also effectively assumes that the transmission investments analyzed by each study do not displace transmission that would need to be built in a reference future without the new wind. In reality, some additional transmission expansion is likely to be needed to accommodate load growth and the addition of other (non-wind) electricity generators.

We present the results from the SSG-WI high renewables scenario, for example, but SSG-WI also evaluated transmission needs in a scenario in which projected load growth is met primarily with gas and in another scenario with increased coal additions. The study found that new transmission would be needed in all three scenarios. In fact, the study found that the high coal scenario required the most transmission investment.

By assuming that these costs are not "avoidable" by the specified wind additions, and by instead attributing the full cost of new transmission in the SSG-WI high renewable scenario to the new generation in that scenario, we overstate the incremental social cost of transmission attributable to wind. In fact, because this limitation is prevalent among the studies in our sample, the estimates for the unit cost of transmission for wind summarized here should not be considered incremental costs, considered in isolation. Instead, they would ideally be compared to similar estimates for the unit cost of transmission association with other generation technologies. 


\section{Text Box 2. Joint System Coordinated Plan (JCSP): Reference Future and 20\% Wind Energy Future}

The Joint System Coordinated Plan is the only study in our sample that produced an explicit "Reference Future" to compare any alternate futures, including a high-wind future. The high wind future in JCSP evaluates the transmission needs in a scenario in which $20 \%$ of the annual energy demand in the study region is met with wind energy. The reference future, on the other hand, evaluates transmission needs in a future with much more modest growth in wind energy. In place of substantial growth in wind energy, the reference future adds significantly more new coal capacity.

Because the JCSP includes a reference future to compare to the high-wind future, we can directly estimate the incremental cost of transmission for wind energy implied by this study; this is not possible in the other studies in our sample which lack reference futures. The total difference in transmission costs in the high-wind future relative to the reference future is $\$ 30.7$ billion, while the total difference in wind energy capacity added in the high-wind future relative to the reference future is $172 \mathrm{GW}$. Thus, the true incremental cost of transmission for wind implied by the JCSP study is $\$ 179 / \mathrm{kW}$.

In contrast, our earlier provided estimate of the unit cost of transmission for wind in which we divided the total transmission cost in the high-wind future ( $\$ 78.6$ billion) by the total new generation additions in that high-wind future $(403 \mathrm{GW})$ led to an estimate of the unit transmission cost of wind of $\$ 195 / \mathrm{kW}$.

Therefore, in the case of the JCSP study, the inherent assumption in our methodology that no transmission would need to be built in the reference future leads to an overstatement of the costs of transmission attributable to wind.

The details provided in the JCSP study also allow us to demonstrate that even though our simplified methodology inherently assumes shared responsibility between all new generation capacity for transmission costs, the limitation did not lead to an overall understatement of the unit costs of transmission attributable to wind. In fact, this analysis has shown that our simplified methodology slightly overstates the unit cost of transmission for wind in the JCSP study.

\subsection{Summary}

Though the limitations of our methodology caution against over-interpretation of the results presented here, it is clear that the transmission costs associated with increased wind development are not insignificant. That said, the estimated median cost adds $\$ 300 / \mathrm{kW}$ to the capital cost of wind-generated electricity. Moreover, it deserves note that transmission expansion is not unique to wind: other generation sources will also require transmission expenditures, not surveyed here. Additionally, transmission expansion typically serves multiple purposes, and our approach to assigning the full costs of that expansion to generation capacity additions effectively ignores those other benefits. Finally, in some of the studies in our sample, transmission is oversized, leading to an overestimate of the transmission costs uniquely associated with the specific wind 
capacity additions. In general, the limitations in our methodology err towards an over-statement of the unit cost of transmission for wind. 


\section{Discussion of Transmission Cost Drivers}

Because the transmission costs surveyed here are, in some cases, sizable, and the range in cost estimates is broad, it is also important to understand how differences in study objectives, methodologies, tools, and assumptions can impact the resulting cost estimates. In particular, among the factors that might be expected to impact the unit cost of transmission for wind are the amount of incremental generation studied and the voltage of new transmission, the length of new transmission, equipment cost assumptions, and differences in study methodologies and objectives.

Each of these factors is discussed below with specific reference to the 40 studies in our sample. Given the diversity of methodologies and assumptions used by these studies, however, teasing out the effects of individual factors is challenging. As such, we discuss the possible impacts of each factor qualitatively, and present illustrative quantitative data, where appropriate. For the purpose of this section, we emphasize the unit cost of wind in $\$ / \mathrm{kW}$-wind terms.

\subsection{Amount of Incremental Generation and Voltage of New Transmission}

The amount of incremental generation capacity that is added in a scenario can be expected to affect the unit cost of transmission in two, opposing ways. First, larger amounts of new capacity developed in a particular region may enable higher voltage transmission lines and therefore benefit from economies of scale, leading to lower unit costs of transmission. We call this the "economies of scale" effect. On the other hand, as more wind capacity is added to the system and lower-cost development prospects are exhausted, unit transmission costs may need to increase to access even more remote wind resource areas. We call this the "supply curve" effect.

We do not find a definitive and systematic trend on this issue, among our sample of studies. It is true that the unit cost of transmission for many of the studies that add a large amount of incremental generation is lower than a number of studies that add less capacity (see Figure 5). All of the studies that evaluate more than $10 \mathrm{GW}$ of incremental generation capacity, for example, have a unit cost of transmission that is less than $\$ 500 / \mathrm{kW}$, while the studies that have a unit cost of transmission above $\$ 1,000 / \mathrm{kW}$ all add between $1.1 \mathrm{GW}$ and $4.0 \mathrm{GW}$ of incremental generation capacity - suggesting an economies of scale effect. At the same time, however, there are a significant number of studies that evaluate less than $10 \mathrm{GW}$ of incremental generation capacity that also have an implied unit costs of transmission of well below $\$ 500 / \mathrm{kW}$.

Furthermore, a pure economies of scale effect would suggest that studies with higher voltage transmission (as that is a primary mechanism for accessing economies of scale in transmission) would generally show lower cost than those studies with lower voltage transmission. While equipment cost assumptions (presented later) show that there is a reduction in the unit cost of transmission capacity with higher voltage lines, we found no systematic dependence of the unit cost of transmission for wind - as calculated with our methodology - on transmission line voltage. ${ }^{29}$ The studies with a unit cost of transmission above $\$ 1,000 / \mathrm{kW}$, for example, all add

\footnotetext{
${ }^{29}$ Specifically, we plotted the line-distance-weighted average transmission voltage with the unit cost of transmission for wind. While many studies with high-voltage transmission did result in relatively low unit transmission costs, there were still numerous studies with high transmission voltages that had much higher unit costs than studies with
} 
transmission lines with a voltage of $500 \mathrm{kV}$, while the lower cost studies that add at least $10 \mathrm{GW}$ of wind add transmission lines with a range of voltages from $345 \mathrm{kV}$ to $800 \mathrm{kV}$.

As such, among our sample at least, a definitive relationship between generation capacity additions and the unit cost of transmission does not appear to exist. This is likely in part a result of the fact that studies differ by important factors including geography, methodology, level of detail, and equipment cost assumptions and therefore do not allow for a perfect test. At a minimum, based on these studies, it does not appear that the unit cost of transmission for wind witnesses a dramatic step increase as penetration levels rise, at least at the penetration levels considered by the studies in our sample. The JCSP study is particularly important for demonstrating that the unit cost of transmission for wind does not dramatically rise even in a scenario that provides enough wind energy to meet $20 \%$ of the energy in a large portion of the Eastern Interconnection. This finding is consistent with that offered by Short and Blair (2005). As discussed there, the reason that the unit cost of transmission does not experience a strong upward trend at higher levels of wind deployment is simple: once dedicated transmission is built to access wind, the wind resource is so large that more transmission can be built at approximately the same cost to access ever increasing levels of wind capacity. This relationship may not be true when only adding wind in a narrow region, but should hold in studies that access a massive wind resource area.

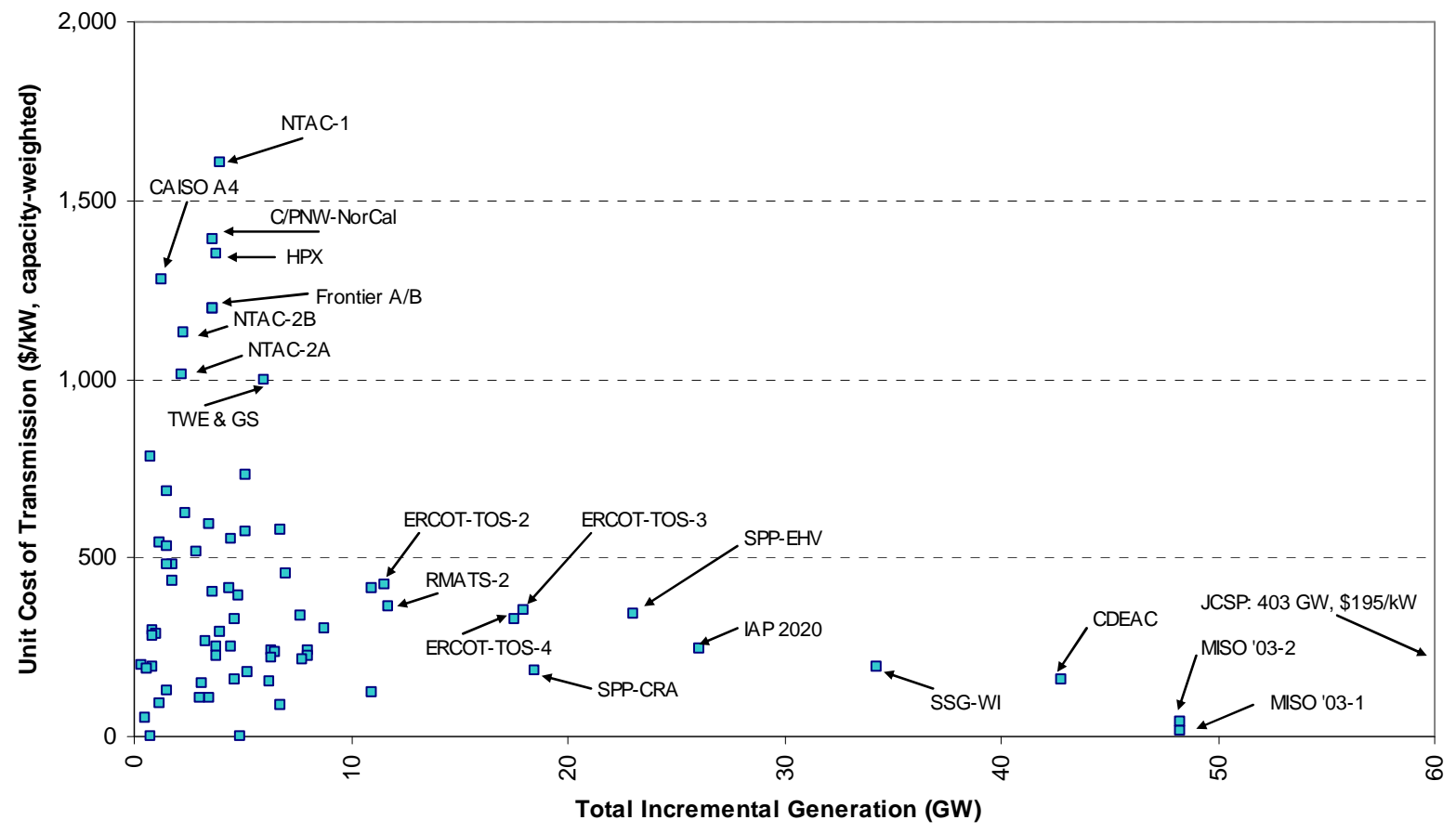

Figure 5. Unit Cost of Transmission vs. Generation Capacity Additions

lower voltages, contrary to the expected result for a simple economies of scale effect. The specific results are not shown here. 


\subsection{Length of Added Transmission}

It might also be expected that as transmission distances increase, the unit cost of transmission would increase, assuming that all else is equal. Again, however, we do not find a definitive and systematic relationship on this issue across the studies in our sample, perhaps in part due to the diversity of studies (see Figure 6). In fact, a number of the studies in our sample add more than three thousand miles of mostly $345 \mathrm{kV}$ and above transmission yet have a unit cost of transmission that is less than many studies that add fewer miles of similar high voltage transmission lines. One of the reasons for this initially counter-intuitive result is that those studies that add the greatest quantity of transmission miles are often adding a substantial quantity of generation capacity as well, thereby reducing the unit cost of transmission. On the other hand, the studies in the upper left corner of Figure 6 add relatively less new generation capacity for the amount of transmission added, leading to a higher estimated unit cost of transmission.

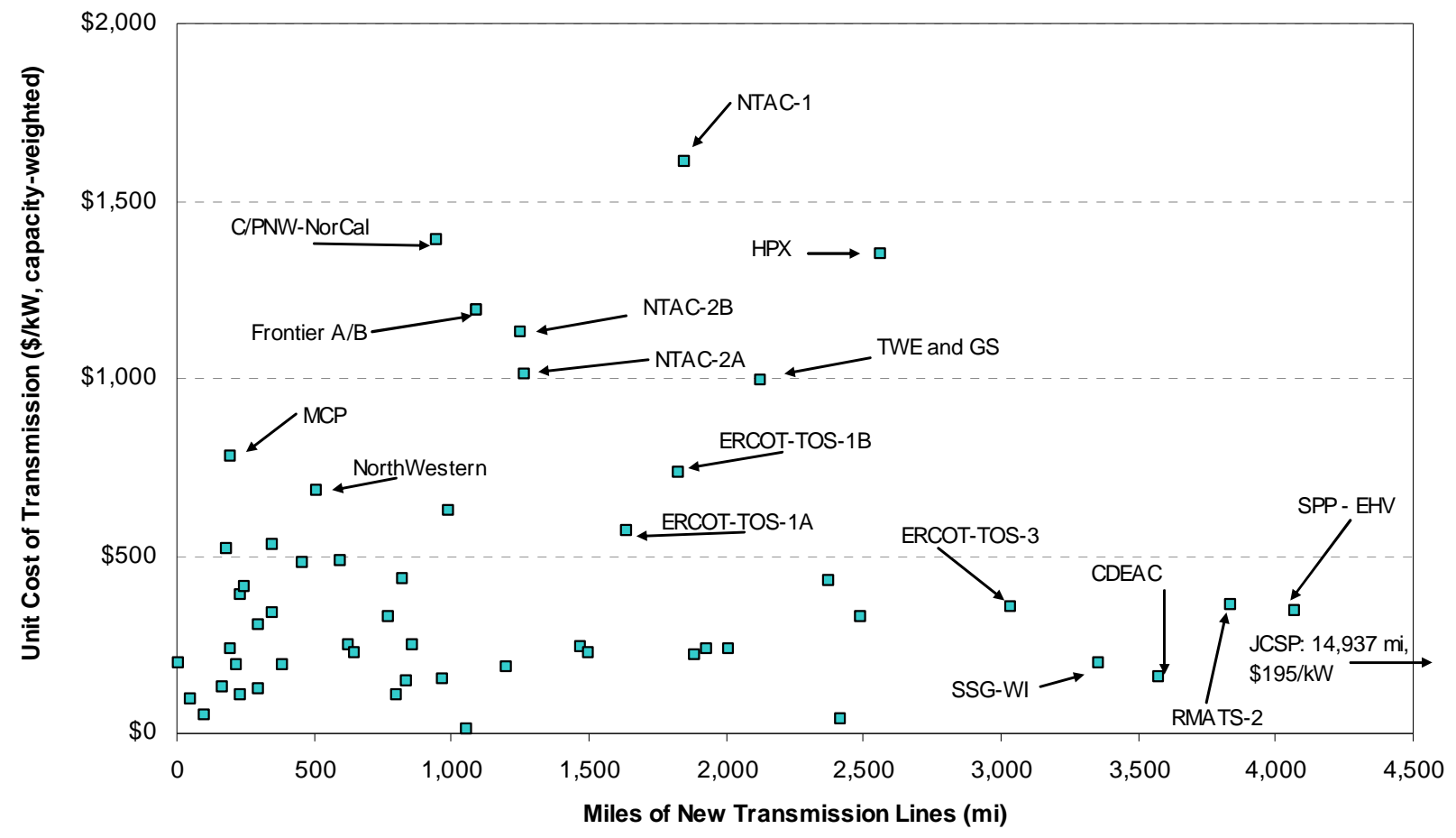

Figure 6. Unit Cost of Transmission vs. Added Transmission Distance

Another way to represent this relationship is to plot the unit cost of transmission against transmission mileage per gigawatt of additional generation capacity, as shown in Figure 7. Lines are included for reference to indicate the implied average cost of transmission equipment. For example, the $\$ 4$ Million/mi line shows points on which a study that had an average equipment cost equivalent to $\$ 4$ Million/mi of new transmission line would fall. Studies that fall on or near the high equipment cost line often include scenarios with double circuit $500 \mathrm{kV}$ lines lines. Studies below the lowest equipment cost line on the other hand, such as the Xcel - BR - Prj scenario, include significant additional low voltage lines or reconductoring of existing lines. As shown, we find that those studies that add significant transmission line distance and relatively little generation capacity tend to have higher unit costs of transmission (represented by points in 
the top right corner) while studies that add more generation for a given distance of new transmission have lower estimated unit costs of transmission (represented by points in the bottom left corner). For example, the JCSP study is in the bottom left corner even though the implied equipment cost is greater than $\$ 4$ Million/mi while the NTAC-2A and -2B studies are in the upper left corner with an implied equipment cost near \$2 Million/mi. A major difference between these two studies is the amount of incremental generation added per distance of transmission line.

One of the factors that may be affecting the relationship in Figure 7 is whether the transmission additions are single, long-distance lines, or instead a number of shorter transmission lines. In the case of many shorter transmission lines, the aggregate transfer capacity may be as high as the sum of the transfer capacity on each line. For example, five lines each 100 miles long with 2 $\mathrm{GW}$ of incremental transfer capacity may allow $10 \mathrm{GW}$ of new generation capacity additions. A single, 500 mile transmission line with a similar $2 \mathrm{GW}$ of transfer capacity, on the other hand, will only allow $2 \mathrm{GW}$ of generation capacity additions. The fact that many of the studies with higher estimated unit costs of transmission focus on single transmission lines that move power over long distances in the West may therefore help explain the relatively high unit cost of transmission in those studies. It should be noted, however, that similar long distance transmission lines sometimes appear as part of a bundle of transmission lines in scenarios with low estimated unit costs of transmission, including those in CDEAC, SSG-WI, and RMATS-2. The length of transmission is therefore clearly not the only factor that leads to the wide range of estimates for the unit cost of transmission presented in this study.

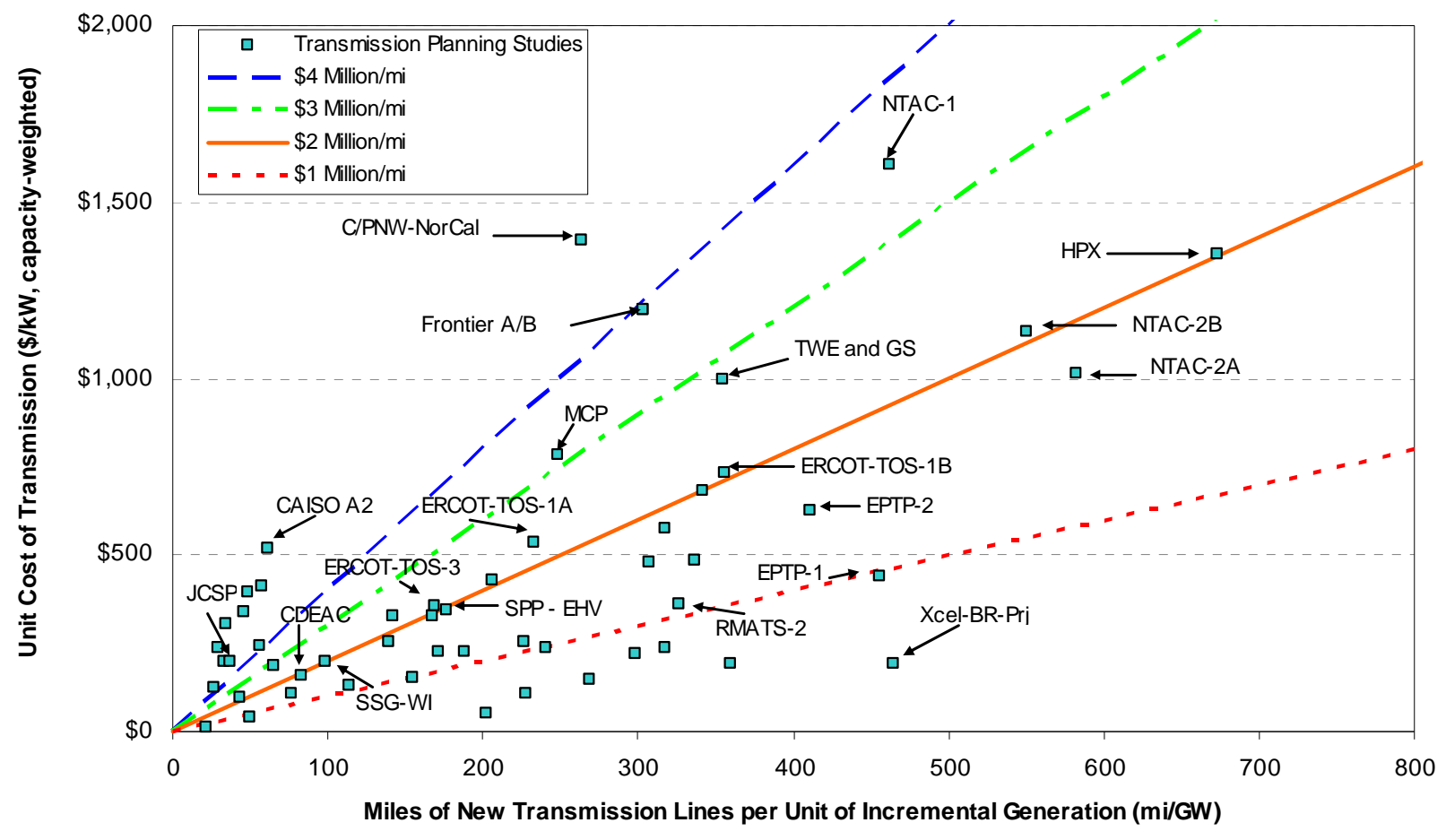

Figure 7. Unit Cost of Transmission vs. Added Transmission Distance per Unit of Incremental Generation 


\subsection{Equipment Cost Assumptions}

Differences in equipment cost assumptions may further contribute to the variation in the implied unit cost of transmission across studies. There are certainly regional factors that affect the cost of transmission equipment, such as regional property values affecting right-of-way costs. With materials, energy, and labor costs changing substantially in recent years, equipment cost assumptions may also be affected by when each individual study was completed. ${ }^{30}$ And finally, there are differences in equipment cost assumptions that can be attributed simply to the level of detail in the study. Highly detailed studies may take into account right-of-way costs, construction costs, financing costs, and taxes, in addition to estimating the cost of all associated equipment such as substations, transformers, and power conditioning equipment. More conceptual studies, on the other hand, may only include transmission line cost and substation costs. The resulting broad range in equipment cost assumptions for those studies that report them are documented in Table 4 (note that many studies did not specify if transmission lines were single or double circuit).

\subsection{Study Methodology and Objectives}

Differences in study methodology and objectives also appear to be key factors in explaining the range in unit transmission costs, especially whether the study takes a "deliverability" focus or a "congestion" focus (as described in Section 2). In particular, many of the studies in our sample that emphasize congestion relief and that therefore allow for redispatch appear to have lower implied estimates of unit transmission costs than somewhat comparable studies that have a deliverability focus. We explore this issue further by qualitatively comparing a subset of the studies in our sample.

Three studies from the Western region (SSG-WI, RMATS, and CDEAC), the ERCOT studies, and the JCSP rely on security constrained economic dispatch models of the entire Western Interconnection, ERCOT, and Eastern Interconnection respectively, when evaluating transmission and wind additions. The implied unit cost of transmission in all of these scenarios is below $\$ 750 / \mathrm{kW}$, despite the fact that these studies evaluate significant amounts of new wind generation and new transmission. Each of these studies employs a more congestion-based focus in their analysis.

Most of the higher cost studies in our sample (with a unit cost above $\$ 1,000 / \mathrm{kW}$ ), however, focus on specific transmission lines between loads and resource areas in the Western region, and do not use a security constrained economic dispatch model to determine which transmission constraints are binding when new wind generation is added. Instead, these studies have a deliverability focus, and rely either on engineering judgment or powerflow cases that assume binding constraints occur during particular time of the year, generally during the summer peak. New transmission is then evaluated to determine by how much it will increase the transfer capacity between the resource region and the target load center during this peak powerflow case,

\footnotetext{
${ }^{30}$ In particular steel prices in the period of 2001-2008 rose on the order of $220 \%$ then began to decline again at the end of 2008. Among our sample of studies, equipment cost assumptions do increase in the more recent studies, but implied the unit cost of transmission for wind among just those studies completed in 2008 had unit costs of transmission that varied by over $630 \%$, indicating that equipment cost increases are not the primary driver of the wide range of unit transmission costs.
} 
subject to plausible contingencies. In most cases, this amount of added transfer capacity is equivalent to the amount of new generation capacity that is assumed to be added in the resource area. In contrast to some of the studies with a congestion focus, the deliverability-focused Western studies do not require time series of location-specific wind production data to determine binding constraints, do not readily allow for redispatch possibilities, and often have an exclusive focus on long-distance transmission from resource areas to specific load centers.

Table 4. Range of Equipment Cost Assumptions

\begin{tabular}{|c|c|c|c|c|}
\hline Equipment & Minimum Cost & Maximum Cost & Unit & $\begin{array}{c}\text { Number of } \\
\text { samples }\end{array}$ \\
\hline \multicolumn{5}{|l|}{ Transmission Lines } \\
\hline 765 kV (no description) & 2.0 & 3.2 & (\$million/mi) & 5 \\
\hline 500 kV (single circuit) & 1.5 & 2.2 & (\$million/mi) & 6 \\
\hline 500 kV (double circuit) & 2.0 & 3.5 & (\$million/mi) & 5 \\
\hline 500 kV (no description) & 0.8 & 2.6 & (\$million/mi) & 10 \\
\hline HVDC Line $(800 \mathrm{kV})$ & & & (\$million/mi) & 1 \\
\hline HVDC Line (345 - 500kV) & 1.1 & 3.0 & (\$million/mi) & 8 \\
\hline HVDC Undersea Cable & & & (\$million/mi) & 1 \\
\hline 345 kV (single circuit) & 0.6 & 1.5 & (\$million/mi) & 4 \\
\hline 345 kV (double circuit) & 1.0 & 2.3 & (\$million/mi) & 5 \\
\hline 345 kV (no description) & 0.5 & 2.2 & (\$million/mi) & 10 \\
\hline 230 kV (double circuit) & & & (\$million/mi) & 1 \\
\hline 230 kV (no description) & 0.3 & 1.6 & (\$million/mi) & 6 \\
\hline $230 \mathrm{kV}$ (rebuild/reconductor) & & & (\$million/mi) & 1 \\
\hline 115 kV (no description) & 0.2 & 0.4 & (\$million/mi) & 2 \\
\hline $115 \mathrm{kV}$ (rebuild/reconductor) & 0.1 & 0.3 & (\$million/mi) & 2 \\
\hline 115 kV (uprate) & 0.05 & 0.4 & (\$million/mi) & 2 \\
\hline \multicolumn{5}{|l|}{ Associated Equipment } \\
\hline HV Substations & 10 & 60 & (\$million/unit) & 6 \\
\hline DC Terminal (\$/MW) & 0.1 & 0.2 & (\$million/MW) & 4 \\
\hline DC Terminal (\$/unit) & 250 & 500 & (\$million/unit) & 5 \\
\hline
\end{tabular}

The different study approaches have even been applied to very similar study scenarios. For example, the Frontier study has a deliverability focus and the RMATS study has a congestion focus, but the Frontier (scenarios A and B) and RMATS-2 scenario both consider the addition of generation resources in Wyoming and large amounts of power transfer to Western load centers over high voltage lines. The Frontier study assumes that all new generation added in Wyoming must transfer its power over the capacity created by a new high voltage line. The RMATS- 2 
study, on the other hand, simulates a coordinated security constrained economic dispatch across the entire Western Interconnection and allows much more new generation to be added in Wyoming (without specifying particular transactions between individual load centers and the new generation).

It is not entirely clear which methodology better represents reality. The approach used in the Frontier study, and many of the other Western studies that have a deliverability focus, effectively assumes that all new generation that will be utilized by distant loads requires transfer capacity over new lines; all existing transmission capacity is assumed to be contractually allocated to other parties. In contrast, coordinated security constrained economic dispatch of the Western Interconnection allows least-cost resources to utilize all transfer paths between resources and loads, as long as transferring the power does not increase production costs. New wind generation in Wyoming, for instance, will initially provide power to nearby loads as long as doing so does not increase costs, and only the remaining wind power will travel to more distant loads. If transmission capacity to any of these loads is limited, wind will either need to be curtailed or transmission will need to be added. Moreover, the amount of power that is transferred over any new long distance lines will depend on how much of that power cannot travel over existing lines without increasing production costs.

Within regions that rely on independent system operators to manage the transmission system, and where those systems are managed based on location-based pricing with few physical transmission rights, the congestion focused approach may better approximate reality. In the West, however, transmission is often physically reserved on a firm point-to-point basis, and much of the transmission capacity in the region is fully reserved, although not necessarily efficiently utilized (see, e.g., Hamilton et al. 2004). Further, state renewable energy portfolio standards sometimes require strict delivery of out-of-state renewable power into specific states. In these instances, use of security constrained economic dispatch models of the Western Interconnection may offer the most economically efficient solution, but may not adequately represent current contractual and operational practices as well as state laws mandating the purchase and delivery of renewable electricity. At the same time, current contractual and operational practices are changing, and FERC Order 890 emphasizes practices to free up underutilized transmission capacity in the region such as planning redispatch and conditional firm transmission service. ${ }^{31}$ Additionally, state renewable energy standards may increasingly allow tradable renewable energy certificates from the broader region, rather than require strict in-state delivery. Given these circumstances, a pure deliverability emphasis may prove unduly conservative. In either case, further work and consideration of these issues would be valuable.

\footnotetext{
${ }^{31}$ Planning redispatch allows a transmission customer that is requesting transmission access over a path that does not have available transmission capacity to pay the higher of the embedded transmission cost rate or the incremental cost to redispatch other generation. Conditional firm transmission allows a transmission customer to access the transmission system with a similar priority as other firm transmission customers except during specific conditions or a pre-specified number of hours of the year. During the conditional period the conditional firm customer can be curtailed at a priority level equivalent to other non-firm customers (NWCC 2007).
} 


\section{Comparison to Top-Down Transmission Cost Estimates}

Though the studies in our sample use different methodologies and varying levels of detail, they all provide a bottom-up approach to transmission planning on a regional basis, based on the specific characteristics and modeling of the electric power grid. In contrast, certain top-down studies are often conducted on a national basis, and are unable to incorporate detailed physical modeling of the transmission system. Such studies must use cruder approaches to estimating the transmission requirements associated with wind deployment.

In this section, we specifically compare the implied unit cost of transmission across the detailed, bottom-up studies in our sample to the results of three, more-conceptual top-down studies. Two of these top-down studies were conducted in the context of the U.S. DOE's analysis of the technical and economic feasibility of achieving $20 \%$ wind electricity penetration in the U.S. The third top-down approach considered here is the EIA's National Energy Modeling System (NEMS), which is used (among other things) to produce the EIA's Annual Energy Outlook.

As shown in the text that follows, the unit cost of transmission in two of the three top-down studies broadly agree with the mid- to lower-end of the range from the bottom-up studies. The unit cost implied in the third top-down study is $50 \%$ greater than the median cost of the studies in our sample. As discussed earlier, the bottom-up estimates likely overstate actual transmission expenditures for wind, perhaps further reinforcing the results of the two lower cost top-down studies. The top-down studies often evaluate much higher levels of wind penetration than assumed in the bottom-up studies, however, making comparisons somewhat inappropriate. ${ }^{32}$ Therefore, perhaps the most that can be concluded is that the top-down studies discussed below do not generate results that are wildly out of line with the more-detailed bottom-up assessments summarized in this report.

\subsection{0\% Wind Energy: AEP 765 kV Overlay}

American Electric Power (AEP) developed a conceptual design for a $765 \mathrm{kV}$ transmission network overlay across the U.S. that could facilitate the wind power additions needed to achieve $20 \%$ wind electricity by 2030 (AEP 2007), as specified in the U.S. DOE's 20\% Wind Energy analysis (U.S. DOE 2008). AEP owns and operates $765 \mathrm{kV}$ lines in the Eastern U.S.

The $765 \mathrm{kV}$ network overlay was developed by connecting $765 \mathrm{kV}$ lines between load centers and areas of high wind potential, using (wherever possible) routes identified in previous regional transmission proposals. Fifty-five wind connection points were identified in the network. The amount of wind installed at each wind connection point was assumed to be equivalent to the

\footnotetext{
${ }^{32}$ As described earlier, however, the unit cost of transmission for wind is unlikely to increase as dramatically as one might initially expect as deployment increases. Additionally, the bottom-up studies, because they are conducted on a regional basis, imply a greater national penetration of wind than might otherwise be expected. As a result, it is not entirely inappropriate to compare the bottom-up, regional transmission plans in our sample to top-down studies that evaluate high levels of national wind power deployment. The JCSP study and many of the studies that add more than $10 \mathrm{GW}$ of new generation are particularly appropriate for comparison and the implied unit costs of transmission in these scenarios are relatively close to the three top-down studies.
} 
transfer capacity of a single $765 \mathrm{kV}$ line. The $765 \mathrm{kV}$ network was designed so that each wind connection point is connected to the $765 \mathrm{kV}$ network overlay through at least two $765 \mathrm{kV}$ lines. The network is therefore designed so that the system would remain within operating limits during contingencies. As specified by AEP, the proposed network included 19,000 miles of 765 $\mathrm{kV}$ line and could accommodate $200-400 \mathrm{GW}$ of wind capacity. The cost of the transmission system was estimated to be $\$ 60$ billion.

The AEP proposal was meant for discussion purposes, and did not involve detailed modeling of the electric power system. AEP's engineering judgment, however, does hold some authority due to the company's experience with developing and building $765 \mathrm{kV}$ lines. Based on our simplified methodology, the unit cost of transmission implied by the AEP $765 \mathrm{kV}$ Overlay is $\$ 150$ - $\$ 300 / \mathrm{kW}$-wind. The low estimate of the unit cost of transmission is $50 \%$ of the median value among the studies in our sample $(\$ 300 / \mathrm{kW}$-wind) and the high estimate is nearly equivalent to the median value in our sample.

\subsection{0\% Wind Energy: Wind Deployment System (WinDS)}

The National Renewable Energy Laboratory used the Wind Deployment System (WinDS) model to evaluate a scenario in which wind provides $20 \%$ of the nation's energy by 2030 , requiring more than $290 \mathrm{GW}$ of additional wind capacity. AEP, as discussed above, provided a companion proposal for the same $20 \%$ wind scenario.

Though WinDS does incorporate a detailed geographic representation of the transmission system and addresses NERC reliability requirements through model constraints, it is based on a transport model rather than a powerflow model. The WinDS model, as employed in U.S. DOE (2008), simply assumed that $10 \%$ of existing transmission capacity was available for wind energy. As wind deployment increases beyond this $10 \%$ limit on existing lines, the model adds new transmission capacity. As a result, for the $20 \%$ scenario, WinDS predicts that $71 \mathrm{GW}$ of new wind will use pre-existing transmission capacity, and that the remainder requires some incremental transmission capacity. ${ }^{33}$ The cost for the new transmission is estimated to be $\$ 60.8$ billion.

Based on our simplified methodology, the unit cost of transmission implied by this study is $\$ 207 / \mathrm{kW}$-wind (U.S. DOE 2008). Clearly, the transmission cost estimates from the WinDS model suggest that vast quantities of wind can be developed in the U.S. without requiring extremely high unit costs of transmission. The $\$ 207 / \mathrm{kW}$-wind figure is $69 \%$ of the median value among the studies in our sample $(\$ 300 / \mathrm{kW}$-wind), is below the implied unit cost of transmission for $70 \%$ of the study scenarios in our sample, and is consistent with the JCSP study and many of the studies that evaluate greater than $10 \mathrm{GW}$ of new generation additions.

\footnotetext{
${ }^{33}$ This assumption may be a bit aggressive based on indications that new transmission must be built in many regions to accommodate a substantial increase in wind energy. Two studies in our sample (NYISO and PSCo) did, however, show that a certain amount of new wind generation can be added to the grid before transmission would need to be upgraded. Most studies did not have the objective of answering the question of how much new wind can be added to the system before transmission upgrades will be required. We therefore cannot use the results from our sample to directly evaluate the merits of this assumption in U.S. DOE (2008).
} 


\subsection{NEMS Long-Term (LT) Multipliers}

The National Energy Modeling System (NEMS) is used by the EIA in its Annual Energy Outlook (AEO), as well as to prepare topical reports for the U.S. Congress and others. The treatment of wind in general, and transmission in particular, has changed somewhat over time. Currently, the transmission cost for wind has been incorporated as a base transmission cost, which is consistent among all generation capacity and includes transmission costs related to load growth, and a wind-specific capital cost multiplier.

In particular, the average base transmission cost adder that is applied to wind capacity by NEMS is $\$ 316 / \mathrm{kW} .{ }^{34}$ In addition to this base transmission cost adder the cost of wind is assumed to further increase as wind is added in a region, due to a variety of factors, including resource degradation, increasingly challenging terrain for developing projects, and additional transmission upgrades above the base transmission cost. The long-term capital cost multiplier in NEMS ranges from one to three times the overnight capital cost of wind additions. For AEO 2008, for example, these multipliers add an additional cost of approximately $\$ 0$ to $\$ 3,370 / \mathrm{kW}^{35}$ to wind, depending on the level of wind deployment in a region (EIA 2008a). The multiplier that applies to each level of deployment in a region (the "step size" of the multipliers) is largely based on analysis from the NREL WinDS model, however several adjustments were applied to the WinDS output to generate the multiplier step sizes actually used in NEMS (PERI 2007). ${ }^{36}$

Because the level of the EIA NEMS multiplier has such a large range, and because the multiplier intends to address multiple issues, of which transmission is only one, it is very difficult to compare the NEMS results with those in our transmission study sample. Nonetheless, the amount of potential wind capacity impacted by these multipliers, by region, is presented in Figure 8 . The figure also shows the amount of regional wind capacity added by 2030 from the AEO 2008 reference case, and therefore depicts the degree to which these estimated capacity additions are affected by the EIA's cost multipliers. ${ }^{37}$

\footnotetext{
${ }^{34}$ The base transmission cost adder varies by region from $\$ 220$ to $\$ 580 / \mathrm{kW}(\$ 2006)$. For wind deployed in 2030 in AEO 2008 the average wind base transmission cost was $\$ 316 / \mathrm{kW}$.

35 The high-cost adder corresponds to the $3 \mathrm{X}$ long-term multiplier of the capital cost, which in the Annual Energy Outlook 2008 was assumed to be $\$ 1,683 / \mathrm{kW}$ (\$2006) for 2030 (EIA 2008b).

${ }^{36}$ The adjustments applied to the WinDS output to create the NEMS long-term multiplier step sizes are based on limits such as the requirement that the resource in the $1 \mathrm{X}$ multiplier step could not be greater than $25 \%$ of the total resource and the cumulative resource in the $1 \mathrm{X}$ and $1.2 \mathrm{X}$ multiplier step could not be greater than $50 \%$ of the total resource. Similar additional limits were applied to the resource size in each multiplier step to reflect the fact that the NEMS multipliers are meant to capture costs that are not included in the WinDS model such as site accessibility, terrain variability, and other market factors (PERI 2007).

${ }^{37}$ Data for determining the average wind base transmission cost and multipliers by 2030 were derived from the Cumulative Installed Capacity (ICapCum) - Year 2030 table in the output file called windsupply08.txt from NEMS. This file was obtained through personal communication with EIA staff.
} 


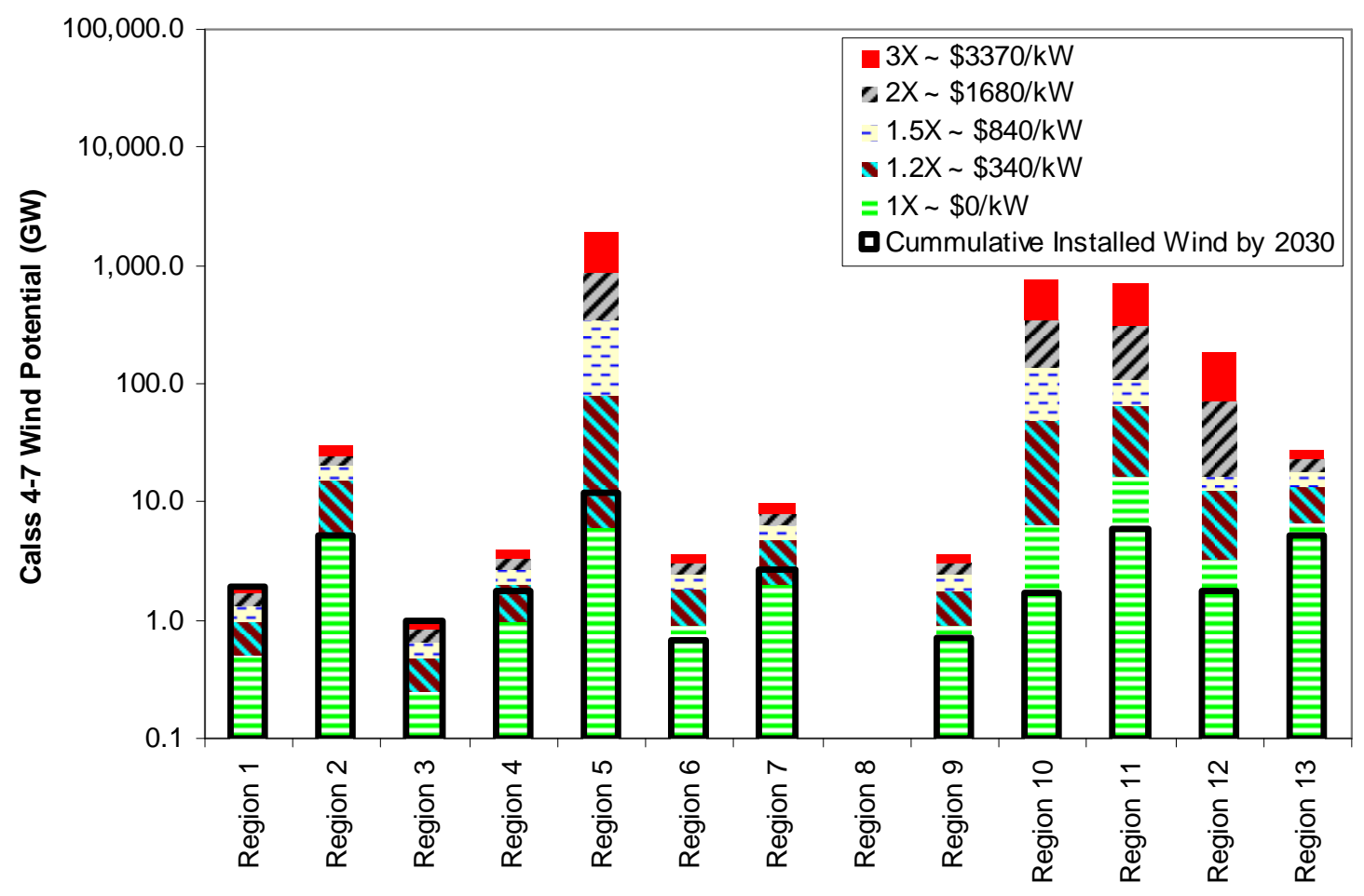

Figure 8. NEMS Long-Term Multiplier Step Sizes and Cumulative Amount of Wind Developed in Each Region by 2030, for AEO 2008 Reference Case ${ }^{38}$

In aggregate, AEO 2008 forecasts $40 \mathrm{GW}$ of new wind capacity by 2030. On average, the multiplier for these wind additions was $1.08 \mathrm{X}$, roughly an additional $\$ 132 / \mathrm{kW}$-wind. Recognizing that the NEMS multiplier is meant to reflect more than just transmission costs, adding the base transmission cost and the long-term multipliers for wind in 2030 leads to a total cost adder of $\$ 449 / \mathrm{kW}$ or $50 \%$ greater than the median unit cost in our sample $(\$ 300 / \mathrm{kW})$.

On a regional basis, the realized NEMS multipliers vary considerably. Regions 1 and 3 (East Central Area and Mid-Atlantic Area), for example, both reach the highest 3X multiplier by 2030, adding $\$ 3,370 / \mathrm{kW}$ to the capital and base transmission cost of incremental wind capacity in those regions. The transmission studies in our sample do not support multipliers at this level, but again, the EIA multipliers intend to capture effects other than transmission. The remaining regions reach only the $1.2 \mathrm{X}$ multiplier (around $\$ 340 / \mathrm{kW}$ additional cost) or remain in the $1 \mathrm{X}$ multiplier step (no additional beyond the base transmission cost) by 2030 in AEO 2008. Many of the bottom-up transmission studies in our sample, as well as the AEP and WinDS results, have an implied unit cost of transmission that is similar to the cost represented by the base

\footnotetext{
${ }^{38}$ Regions are defined as follows: East Central Area Reliability Coordination Agreement - 01; Electric Reliability Council of Texas - 02; Mid-Atlantic Area Council - 03; Mid-America Interconnected Network - 04; MidContinent Area Power Pool - 05; Northeast Power Coordinating Council / New York - 06; Northeast Power Coordinating Council / New England - 07; Florida Reliability Coordinating Council - 08; Southeastern Electric Reliability Council - 09; Southwest Power Pool - 10; Western Electricity Coordinating Council / Northwest Power Pool Area-11; Western Electricity Coordinating Council / Rocky Mountain Power Area and Arizona-New MexicoSouthern Nevada Power Area - 12; Western Electricity Coordinating Council / California - 13
} 
transmission cost adder in NEMS (\$300/kW median for our sample versus a $\$ 316$ base transmission cost for wind in NEMS). 


\section{Conclusions}

Recent growth in wind power development in the United States has been coupled with a growing concern that this development will require substantial additions to the nation's transmission infrastructure. It is clear that institutional issues related to transmission planning, siting, and cost allocation will pose major obstacles to accelerated wind power deployment, but also of concern is the potential cost of this transmission infrastructure build out.

In this report, we have reviewed a sample of 40 regional transmission studies that have included wind power. These studies vary considerably in scope, authorship, objectives, and methodology, making comparisons difficult. Regardless, our analysis of these studies reveals considerable differences in the implied unit cost of transmission for wind. In particular, the total range in unit transmission costs for wind implicit in these studies is from $\$ 0 / \mathrm{kW}$ to over $\$ 1,500 / \mathrm{kW}$, though some of this range is surely the result of flaws in our methodological approach.

The majority of studies in our sample, however, have a unit cost of transmission that is below $\$ 500 / \mathrm{kW}$, or roughly $25 \%$ of the current $\$ 2,000 / \mathrm{kW}$ capital cost of building a wind project. The median cost of transmission across all scenarios in our sample is $\$ 300 / \mathrm{kW}$, on a capacityweighted basis; roughly $15 \%$ of the current cost of building a wind project or $23 \%$ of the cost of building a wind project in the early 2000s. In terms of cost per megawatt-hour of wind power generation, the median cost is $\$ 15 / \mathrm{MWh}$ on a capacity-weighted basis, and most studies fall below \$25/MWh. Two highly-conceptual, top-down studies of $20 \%$ wind power penetration in the U.S. electricity system have implied unit costs of transmission below or nearly equivalent to the median cost of our sample of 40 bottom up transmission planning studies.

These mid-range costs, though not insignificant, are also not overwhelming. Additionally, the limitations of our methodology likely err towards an over-statement of the unit cost of transmission for wind. The need for transmission expansion, for example, is not unique to wind: other generation sources will also require transmission expenditures. Transmission expansion also typically serves multiple purposes, and our approach to assigning the full costs of that expansion to generation capacity additions effectively ignores those other benefits. And, in at least some of the studies in our sample, transmission is oversized, leading to an over-estimate of the transmission costs uniquely associated with wind additions. Finally, in taking a deliverability (rather than congestion) focus, a number of the studies in our sample reflect existing contractual limits that, if overcome, could increase the efficiency of grid operations and lower the unit cost of transmission for wind; further work on this specific issue is merited.

Because the range of transmission costs surveyed here is broad, however, with a number of highcost scenarios, it is also important to understand how differences in study objectives, methodologies, and assumptions can impact the resulting cost estimates. Our work has only begun that process, and far more comparative work is needed. Transmission costs do appear to be high in cases where long transmission lines are added without accessing substantial amounts of new generation. At the same time, we find little evidence that higher levels of wind penetration require dramatically increased unit transmission costs, relative to more-moderate levels of wind deployment. This seems to be confirmed by two top down scenarios of $20 \%$ wind 
energy in the U.S., the JCSP study of $20 \%$ wind energy in the Eastern Interconnection, and by a number of bottom up study scenarios that add greater than $10 \mathrm{GW}$ of new generation. It therefore appears that the unit cost of transmission for wind need not increase dramatically at higher levels of wind penetration. 


\section{References}

American Electric Power (AEP). 2007. Interstate Transmission Vision for Wind Integration. White Paper. October. http://www.aep.com/about/i765project/docs/WindTransmissionVisionWhitePaper.pdf

Auer, H., M. Stadler, G. Resch, C. Huber, T. Schuster, H. Taus, L.H. Neilsen, J. Twidell, and D. J. Swider. 2004. Cost and Technical Constraints of RES-E Grid Integration: Work Package 2. GreenNet: Pushing a Least Cost Integration of Green Electricity into the European Grid. August. http://www.risoe.dk/rispubl/SYS/syspdf/wp2_greennet.pdf.

California ISO (CAISO). 2006. Proposal to Remove Barriers to Efficient Transmission Investment. http://www.caiso.com/188d/188d7ee0ae42.pdf

Cavallo, A. 2007. Controllable and affordable utility-scale electricity from intermittent wind resources and compressed air energy storage (CAES). Energy 32, no. 2 (February): 120127.

Clean and Diversified Energy Advisory Committee (CDEAC) Transmission Task Force. 2006. Report of the Transmission Task Force to the Western Governors Association. March. http://www.westgov.org/wga/initiatives/cdeac/TransmissionReport-final.pdf

Czisch, G. and G. Giebel. 2000. "A Comparison of Intra- and Extraeuropean Options for an Energy Supply with Wind Power," Conference on Wind Power for the $21^{\text {st }}$ Century, Kassel, Germany. September

DeCarolis, J. F., and D. W. Keith. 2006. The economics of large-scale wind power in a carbon constrained world. Energy Policy 34, no. 4 (March): 395-410.

Energy Information Administration (EIA). 2008a. Model Documentation Renewable Fuels Module of the National Energy Modeling System. Washington, D.C.: Energy Information Administration. http://tonto.eia.doe.gov/ftproot/modeldoc/m069(2008).pdf

Energy Information Administration (EIA). 2008b. Assumptions to the Annual Energy Outlook 2008. Washington, D.C.: Energy Information Administration. http://www.eia.doe.gov/oiaf/aeo/assumption/pdf/0554(2008).pdf

European Wind Energy Association (EWEA). 2005. Large Scale Integration of Wind Energy in the European Power Supply: Analysis, Issues, and Recommendations. Prepared by the European Wind Energy Association. http://www.ewea.org/fileadmin/ewea_documents/documents/publications/grid/051215_G rid_report.pdf 
Federal Energy Regulatory Commission (FERC). 2008. “Order on Technical Conference. Docket No. AD08-2-000.” March 20, 2008. Washington, D.C.: Federal Energy Regulatory Commission. http://www.ferc.gov/whats-new/comm-meet/2008/032008/E-27.pdf

Federal Energy Regulatory Commission (FERC). 2007. "Preventing Undue Discrimination and Preference in Transmission Service.” Washington, D.C.: Federal Energy Regulatory Commission. http://www.ferc.gov/whats-new/comm-meet/2007/021507/E-1.pdf

Greenblatt, J. B., S. Succar, D. C. Denkenberger, R. H. Williams, and R. H. Socolow. 2007. Baseload wind energy: modeling the competition between gas turbines and compressed air energy storage for supplemental generation. Energy Policy 35, no. 3 (March): 14741492.

Hamilton, R., R. Lehr, D. Olsen, J. Neilsen, T. Acker, M. Milligan, and H. Geller. 2004. "Integrating Wind into Transmission Planning: The Rocky Mountain Area Transmission Study (RMATS).” NREL/CP-500-35969. Global WindPower Conference. Chicago, Illinois. http://www.nrel.gov/docs/fy04osti/35969.pdf

Hirst, E. 2004. U.S. Transmission Capacity: A Review of Transmission Plans. The Electricity Journal,17 (7): 65-79.

Hirst, E, and B. Kirby. 2002. Expanding Transmission Capacity: A Proposed Planning Process. The Electricity Journal. 15 (8): 54-59.

Hirst, E, and B. Kirby. 2001a. Key Transmission Planning Issues. The Electricity Journal, 14 (8): 59-70.

Hirst, E, and B. Kirby. 2001b. Transmission Planning for a Restructuring U.S. Electricity Industry. Washington, D.C.: Edison Electric Institute. http://www.eei.org/industry_issues/energy_infrastructure/transmission/transmission_hirst .pdf

Jacobs, M.B. 2007. Transmission Recommendations for High Wind Penetration. In Power Engineering Society General Meeting, 2007. IEEE, 1-6.

Joskow, P.L. 2005a. Transmission Policy in the United States. Utilities Policy 13 (2005) 95-115

Joskow, P.L. 2005b. Patterns of Transmission Investment. MIT CEEPR WP-2005-004, March. http://web.mit.edu/ceepr/www/2005-012.pdf

Lesieutre, B. C., and J. H. Eto. 2004. When a Rose Is Not a Rose: A Review of Recent Estimates of Congestion Costs. The Electricity Journal 17, no. 4 (May): 59-73.

Lew, D., R. H. Williams, S. Xie, and S. Zhang.1998. Large-scale baseload wind power in China. Natural Resources Forum 22(3), 165-184. 
National Grid. 2006. Transmission and Wind Energy: Capturing the Prevailing Winds for the Benefit of Customers. September. http://www.nationalgridus.com/non_html/c33_NG_wind_policy.pdf

North American Electric Reliability Corporation (NERC). 2008. Long Term Reliability Assessment: 2008-2017. Princeton, NJ, October. http://www.nerc.com/files/LTRA2008.pdf

National Wind Coordinating Committee (NWCC). 2007. FERC Order 890: What Does It Mean For the West? NWCC Bi-Monthly Transmission Update. http://www.nationalwind.org/publications/transmission/updates/ferc890.pdf

Olsen, D. 2007. "Renewables-First Generation/Transmission Projects.” Windpower 2007 Conference. Los Angeles, CA, June 6. http://www.interwest.org/documents/documents/2007-06-06_olsen.pdf.

Osborn, D, and J. Wilson. 2007. "Inclusion of Wind in the MISO Transmission Expansion Planning Process.” Power Engineering Society General Meeting, 2007. IEEE, 1-4

Porter, K. and S. Fink. 2008. State Transmission Infrastructure Authorities: The Story So Far. National Renewable Energy Laboratory. NREL/ SR-500-43146. May. http://www.nrel.gov/docs/fy08osti/43146.pdf

Princeton Energy Resources International (PERI). 2007. Revising the Long Term Multipliers in NEMS: Quantifying the Incremental Transmission Costs Due to Wind Power. Rockville, MD, May 23. http://www.perihq.com

Short, W. and N. Blair. 2005. How Much Does Wind Energy Access, Transmission, and Intermittency Really Cost? Supply Curves for Electricity Generation from Wind. Golden, Colorado: National Renewable Energy Laboratory. http://www.nrel.gov/analysis/winds/pdfs/winds_supply_curves.pdf

Stoft, S., C. Webber, and R. Wiser. 1997. Transmission Pricing and Renewables: Issues, Options, and Recommendations. LBNL-39845. Berkeley, California: Lawrence Berkeley National Laboratory. http://eetd.lbl.gov/ea/EMS/reports/39845.pdf

Strbac, G., D. Pudjianto, M. Castro, P. Djapic, B. Stojkovska, C. Ramsay, R. Allan. 2007. Transmission Investment, Access and Pricing in Systems with Wind Generation. DTI Centre for Distributed Generation and Sustainable Electrical Energy, February. http://www.sedg.ac.uk/

Swider, D. J., L. Beurskens, S. Davidson, J. Twidell, J. Pyrko, W. Prüggler, H. Auer, K. Vertin, R. Skema. 2008. Conditions and costs for renewables electricity grid connection: Examples in Europe. Renewable Energy 33, no. 8 (August): 1832-1842. 
U.S. Department of Energy (DOE). 2008. 20\% Wind Energy by 2030: Increasing Wind Energy's Contribution to U.S. Electricity Supply. Washington, D.C.: U.S. Department of Energy. http://www.20percentwind.org/20percent_wind_energy_report_05-11-08_wk.pdf

U.S. Department of Energy (DOE). 2006. National Electric Transmission Congestion Study. U.S. Department of Energy, August. http://nietc.anl.gov/documents/docs/Congestion_Study_2006-9MB.pdf.

U.S. Department of Energy (DOE). 2002. National Transmission Grid Study. Washington, D.C.: U.S. Department of Energy, May. http://eetd.lbl.gov/certs/ntgs/main-print.pdf

Vajjhala, S., A. Paul, R. Sweeney, and K. Palmer. 2008. Green Corridors: Linking Interregional Transmission Expansion and Renewable Energy Policies. Discussion Paper. Washington, D.C.: Resources for the Future, March. http://www.rff.org/focus_areas/features/Documents/RFF-DP-08-06.pdf

WIRES and CRA International. 2008. Integrating Locationally-constrained Resources into Transmission: A Survey of US Practices. October. http://www.wiresgroup.com/resources/industry_reports/WIRES_Report_LCR.pdf

Wiser, R., and M. Bolinger. 2008. Annual Report on U.S. Wind Power Installation, Cost, and Performance Trends: 2007. LBNL-275-E. Berkeley, California: Lawrence Berkeley National Laboratory. http://eetd.lbl.gov/EA/EMS/reports/lbnl-275e.pdf 


\section{Transmission Reports}

Arizona Public Service (APS), PacifiCorp, National Grid, Wyoming Infrastructure Authority. 2008. Transwest Express and Gateway South, Regional Stakeholder Meeting. January. https://transwest.azpsoasis.com/docs/2008_01_23_TWE_GS_Regional_Stakeholder_Me eting.pdf

California ISO (CAISO). 2008. Report on Preliminary Renewable Transmission Plans. California Independent System Operator, August 6. http://www.caiso.com/2007/2007d75567610.pdf

California ISO (CAISO). 2006. CAISO South Regional Transmission Plan for 2006 (CSRTP2006) Part II: Findings and Recommendations on the Tehachapi Transmission Project. Regional Transmission - South Planning and Infrastructure Development California ISO. December. http://www.caiso.com/18db/18dbaedf2cca0.pdf

California Public Utilities Commission (CPUC) Energy Division. 2003. Electric Transmission Plan for Renewable Resources in California: Report to the Legislature. California Public Utilities Commission. http://docs.cpuc.ca.gov/word_pdf/REPORT/32197.pdf

CapX 2020. 2005. CapX 2020 Technical Update: Identifying Minnesota's Electric Transmission Infrastructure Needs. May. http://www.capx2020.com/documents.html

CapX 2020. 2007. Community Based Energy Development Transmission Study: West Central (Minnesota) Transmission Planning Zone. January. http://www.capx2020.com/documents.html

Clean and Diversified Energy Advisory Committee (CDEAC) Transmission Task Force. 2006. Report of the Transmission Task Force to the Western Governors Association. March. Available at: http://www.westgov.org/wga/initiatives/cdeac/TransmissionReport-final.pdf

Colorado Long Range Transmission Planning Group (CLRTPG). 2006. Colorado Long Range Transmission Planning Study: 2005 - 2015. http://www.oatioasis.com/TSGT/TSGTdocs/CLRTP_G2015ReportJuly06.pdf

CRA International. 2008. First Two Loops of SPP EHV Overlay Transmission Expansion: Analysis of Benefits and Costs. September 28. http://www.crai.com/uploadedFiles/RELATING_MATERIALS/Publications/BC/Energy and_Environment/files/Southwest\%20Power\%20Pool\%20Extra-HighVoltage\%20Transmission\%20Study.pdf

Electric Reliability Council of Texas (ERCOT). 2008. Competitive Renewable Energy Zones Transmission Optimization Study. ERCOT System Planning, April. http://www.ercot.com/news/presentations/ 
Electric Reliability Council of Texas (ERCOT). 2006. Analysis of Transmission Alternatives for Competitive Renewable Energy Zones in Texas.

http://www.ercot.com/news/presentations/2006/ATTCH_A_CREZ_Analysis_Report.pdf

GE Power Systems Energy Consulting. 2004. The Effects of Integrating Wind Power on

Transmission System Planning, Reliability, and Operations: Report on Phase 1. Albany, NY: New York State Energy Research and Development Authority (NYSERDA), February. http://www.uwig.org/phase\%20_1_feb_02_04.pdf

HPX Participants. 2008. High Plains Express Transmission Project: Feasibility Study Report. June. http://www.rmao.com/wtpp/HPX/HighPlainsExpress\%20First\%20Stage\%20Feasibility\% 20Report\%2006_08.pdf

ISO New England Inc. 2007. New England Electricity Scenario Analysis: Exploring the economic, reliability, and environmental impacts of various resource outcomes for meeting the region's future electricity needs. ISO New England Inc., August. http://www.isone.com/committees/comm_wkgrps/othr/sas/mtrls/elec_report/scenario_analysis_final.pdf

Krzykos, P. 2008. Southwest Area Transmission (SWAT) Oversight Committee-Arizona Renewable Transmission Task Force: Presentation. http://www.westconnect.com/documents_detail.php?fileid=477

K.R. Saline \& Assoc. 2008. 2007 WestConnect Transmission Plan: A Report Detailing the Electrical Transmission System Expansion Plan Within the WestConnect Planning Area During the 2008-2017 Timeframe. WestConnect, January 5. http://www.westconnect.com/filestorage/WestConnect_Transmission_Plan_FINAL.pdf

Maine Public Service and Central Maine Power Company. 2008. Request for Certificate of Public Convenience and Necessity to Construct the Maine Power Connection ("MPC") to Enable Interconnection of Aroostook Wind Energy Project. State of Maine Public Utilities Commission, July 1. http://mpuc.informe.org/easyfile/cache/easyfile_doc207274.pdf

Midwest ISO (MISO). 2008. Joint Coordinated System Plan: Economic Assessment Wrap-up Stakeholder Meeting. December 10, Dallas, TX. http://www.jcspstudy.org/

Midwest ISO (MISO). 2007. Midwest Transmission Expansion Plan 2006. February. http://www.midwestiso.org/page/Expansion+Planning

Midwest ISO (MISO). 2003. Midwest Transmission Expansion Plan 2003. June. http://www.midwestiso.org/page/Expansion+Planning

Montana-Alberta Tie Line LTD. (MATL). 2006. Montana-Alberta Tie 230 kV Transmission Line: Transmission Development Facilities Application, Volume One. Alberta Energy 
and Utilities Board (EUB).

http://www.ercb.ca/docs/applications/submissions/1458443/Ex\%20002-02.pdf

NorthWestern Energy. 2008. Mountain States Transmission Intertie ("MSTI"): Phase 1 Comprehensive Progress Report. http://www.oatioasis.com/NWMT/

NorthWestern Energy. 2007. Mountain States Transmission Intertie (MSTI) Open Season Update Meeting. www.oatioasis.com/NWMT/NWMTdocs/MSTI_Open_Season_Update_Mtg_Dec_5_200 7.ppt

NorthWestern Energy. 2005. Montana - Idaho Path Open Season Study Report. http://www.oatioasis.com/NWMT/NWMTdocs/OpenSeasonStudyReport-Final.pdf

NW Transmission Assessment Committee (NTAC), Canada-NW-Cal Study Group. 2006. Canada-Northwest-California Transmission Options Study. May. http://209.221.152.82/ntac/publications.html

PG\&E. 2007a. WECC Regional Planning Review: Canada/Pacific Northwest - Northern California Transmission Line Project, Technical Analysis Committee Report. http://www.pge.com/includes/docs/pdfs/mybusiness/customerservice/nonpgeutility/electr ictransmission/weccplanning/finaltacreport.pdf

PG\&E. 2007b. Canada/Pacific Northwest to Northern California Electric: WECC Regional Planning Project, Economic Analysis Committee. http://www.pge.com/includes/docs/pdfs/mybusiness/customerservice/nonpgeutility/electr ictransmission/weccplanning/finaleacreport.pdf

Porter, K. and Intermittency Analysis Project Team. 2007. Intermittency Analysis Project: Summary of Final Results. California Energy Commission, PIER Research Development \& Demonstration Program. CEC-500-2007-081. http://www.energy.ca.gov/pier/final_project_reports/CEC-500-2007-081.html

Rocky Mountain Area Transmission Study (RMATS). 2004. Rocky Mountain Area Transmission Study. September 2004. http://psc.state.wy.us/htdocs/subregional/Reports.htm

Quanta Technology, LLC. 2008. Final Report on the Southwest Power Pool (SPP) Updated EHV Overlay Study. March.

http://www.spp.org/publications/Quanta_Technology_March_2_2008_Update_to the_E HV_Study_Final_Report.pdf

Seams Steering Group-Western Interconnection (SSG-WI). 2003. Framework for Expansion of the Western Connection Transmission System. October. 
Securities Exchange Commission (SEC). 2008. Form 10-K: Xcel Energy Inc. http://www.sec.gov/Archives/edgar/data/72903/000104746908001516/a2182843z10k.htm\#toc_de73301_7 (Actual cost of transmission proposed in Xcel Energy 2001).

Southern California Edison Company (SCE). 2007. SCE 2008 Conceptual Transmission Requirements and Costs for Integrating Renewable Resources. September.

Southwest Power Pool (SPP). 2008. Oklahoma Electric Power Transmission Task Force (OEPTTF) Study. SPP Engineering Department, Planning Section, March. http://www.spp.org/publications/OEPTTF\%20Report_FINAL_4_22_08_updated.pdf.

Southwest Power Pool (SPP), Engineering Staff. 2007. SPP Transmission Expansion Supplement to Support Development of Competitive Renewable Energy Zones. Submitted to the Public Utility Commission of Texas, Docket No. 33672. April. http://sppoasis.spp.org/documents/swpp/transmission/CREZ_April_07.pdf

Southwest Power Pool (SPP), Engineering Staff. 2006. Southwest Power Pool Inc. Analysis of Transmission Alternatives for Competitive Renewable Energy Zones in Texas. Submitted to the Public Utility Commission of Texas, Docket No. 33672. December. http://sppoasis.spp.org/documents/swpp/transmission/SPP\%20CREZ\%20Study\%20FIN AL\%20122906.pdf

Southwest Power Pool (SPP). 2005. Kansas/Panhandle Sub-Regional Transmission Study. May. http://www.spp.org/publications/Kansas_Panhandle_Study.pdf

Tri-state Generation and Transmission, and Western Area Power Administration. 2006. Preliminary Report: Eastern Plains Transmission Project $500 \mathrm{kV}$ and $345 \mathrm{kV}$ Comparison. March 31. http://www.oatioasis.com/TSGT/TSGTdocs/EPTP_VoltageOptions_033106.pdf

Western Regional Transmission Expansion Partnership (WRTEP), Economic Analysis Subcommitee. 2007. Benefit-Cost Analysis of Frontier Line Possibilities. April. http://www.ftloutreach.com

Xcel Energy Transmission Planning (Xcel). 2006. Wind Integration Study Report Of Existing and Potential 2003 Least Cost Resource Plan Wind Generation. Xcel Energy http://www.rmao.com/wtpp/Misc_Info/2008\%20Wind\%20Integration\%20Study.pdf

Xcel Energy, Transmission Reliability \& Assessment. 2005. Buffalo Ridge Incremental Generation Outlet Electric Transmission Study. May. http://www.rmao.com/xfpp/nsp_meeting_materials/20050517-MoBasinSPGBuffaloRidgeStudy-Meeting-NSP-doc3-BRIGO\%20Study\%20Report.pdf

Xcel Energy. 2001. Application for Certificates of Need for Transmission Lines to Support the Development of Wind Powered Generation in Southwestern Minnesota. Certificate of Need. Minneapolis, Minnesota: Minnesota Public Utilities Commission, December 28. 